\title{
Capital Structure Arbitrage Model Choice and Volatility Calibration
}

\author{
Bajlum, Claus; Tind Larsen, Peter
}

Document Version

Final published version

Publication date:

2007

License

CC BY-NC-ND

Citation for published version (APA):

Bajlum, C., \& Tind Larsen, P. (2007). Capital Structure Arbitrage: Model Choice and Volatility Calibration. Aarhus Universitetsforlag.

Link to publication in CBS Research Portal

\section{General rights}

Copyright and moral rights for the publications made accessible in the public portal are retained by the authors and/or other copyright owners and it is a condition of accessing publications that users recognise and abide by the legal requirements associated with these rights.

Take down policy

If you believe that this document breaches copyright please contact us (research.lib@cbs.dk) providing details, and we will remove access to the work immediately and investigate your claim. 


\title{
Capital Structure Arbitrage: Model Choice and Volatility Calibration*
}

\author{
Claus Bajlum ${ }^{\dagger} \quad$ Peter Tind Larsen ${ }^{\ddagger}$ \\ Current Version: May 29, 2007 \\ First Draft: August 28, 2006
}

\begin{abstract}
When identifying relative value opportunities across credit and equity markets, the arbitrageur faces two major problems, namely positions based on model misspecification and mismeasured inputs. Using credit default swap data, this paper addresses both concerns in a convergence-type trading strategy. In spite of differences in assumptions governing default and calibration, we find the exact structural model linking the markets second to timely key inputs. Studying an equally-weighted portfolio of all relative value positions, the excess returns are insignificant when based on a traditional volatility from historical equity returns. However, relying on an implied volatility from equity options results in a substantial gain in strategy execution and highly significant excess returns - even when small gaps are exploited. The gain is largest in the speculative grade segment, and cannot be explained from systematic market risk factors. Although the strategy may seem attractive at an aggregate level, positions on individual obligors can be very risky.
\end{abstract}

\footnotetext{
${ }^{*}$ We thank Lombard Risk for access to the credit default swap data. We are grateful to Peter Løchte Jørgensen, David Lando, Hayne Leland, Svein-Arne Persson, Stephen Schaefer, Ilya Strebulaev, Carsten Sørensen, participants at the C.R.E.D.I.T. 2006 Doctoral Tutorial in Venice, the Danish Doctoral School of Finance Workshop 2007, a Credit Risk Workshop at Aarhus School of Business, the Nordic Finance Network Workshop 2007 in Helsinki and seminar participants at University of Aarhus and Aarhus School of Business for useful discussions and comments. Any remaining errors are our own.

${ }^{\dagger}$ Danmarks Nationalbank and Copenhagen Business School, Department of Finance, Solbjerg Plads, 2000 Frederiksberg, Denmark. E-mail: cb.fi@cbs.dk, tel.: +45 38153579.

${ }^{\ddagger}$ School of Economics and Management, University of Aarhus, Universitetsparken 322, 8000 Aarhus C, Denmark. E-mail: plarsen@econ.au.dk, tel.: +45 89422139.
} 


\section{Introduction}

Capital structure arbitrage refers to trading strategies that take advantage of the relative mispricing across different security classes traded on the same capital structure. As the exponential growth in the credit default swap (CDS) market has made credit much more tradable and traditional hedge fund strategies have suffered declining returns (Skorecki (2004)), important questions arise for hedge funds and proprietary trading desks. In particular, do credit and equity markets ever diverge in opinion on the quality of an obligor? What is the risk and return of exploiting divergent views in relative value strategies? Although trading strategies founded in a lack of synchronicity between equity and credit markets have gained huge popularity in recent years (Currie \& Morris (2002) and Zuckerman (2005)), the academic literature addressing capital structure arbitrage is very sparse.

This paper conducts a comprehensive analysis of the risk and return of capital structure arbitrage using CDS data on 221 North American obligors in 2002 to 2004. When looking at one security in order to signal the sale or purchase of another, the resulting link and initiation of a trade depends on the chosen model. We address two major problems facing the arbitrageur, namely relative value opportunities driven by model misspecification or mismeasured inputs.

Duarte, Longstaff \& Yu (2005) analyze traditional fixed income arbitrage strategies such as the swap spread arbitrage, but also briefly address capital structure arbitrage. Yu (2006) cites a complete lack of evidence in favor of or against strategies trading equity instruments against CDSs. Hence, he conducts the first analysis of the strategy by implementing the industry benchmark CreditGrades using a historical volatility, which is a popular choice among professionals. ${ }^{1}$

We show that the more comprehensive model by Leland \& Toft (1996) only adds an excess return of secondary order. However, when exploiting a wider array of inputs and securities in model calibration and identification of relative value opportunities, the result is a substantial improvement in strategy execution and returns.

When searching for relative value opportunities, the arbitrageur uses a structural model to gauge the richness and cheapness of the 5-year CDS spread. Using the market value of equity, an associated volatility measure and the liability structure of the obligor, he compares the spread implied from the model with the market

\footnotetext{
${ }^{1}$ That CreditGrades is the preferred framework among professionals is argued in Currie \& Morris (2002) and Yu (2006), while the CreditGrades Technical Document by Finger (2002) advocates for the 1000-day historical volatility.
} 
spread. When the market spread is substantially larger(smaller) than the theoretical counterpart, he sells(buys) a CDS and sells(buys) equity. If the market and equity-implied spread from the model subsequently converge he profits. Hence, the model helps identify credits that either offer a discount against equities or trade at a very high level.

As pointed out in Duarte et al. (2005), capital structure arbitrage hinges on models that can explain the link between securities with different characteristics. In fact, the chosen underlying model plays a central role in all parts of the strategy. First, it is used to calculate equity-implied CDS spreads governing entry and exit decisions in equity and credit markets. Second, to calculate daily returns on an open position, it is necessary to keep track on the total value of an outstanding CDS position. This is done from the model-based term structure of survival probabilities. Third, the model is used to calculate the equity hedge by a numerical differentiation of the value of the CDS position wrt. the equity price.

CreditGrades loosely builds on Black \& Cox (1976), with default defined as the first passage time of firm assets to an unobserved default barrier. This model, like other structural models, is based on a set of restrictive assumptions regarding the default mechanism and capital structure characteristics.

Although allowing for a random recovery, CreditGrades belongs to the class of models with an exogenous default barrier. However, Leland (1994) subsequently extended in Leland \& Toft (1996) has pioneered models with endogenous default. In these models, the default barrier is chosen by managers as the asset value where it is no longer optimal for the equityholders to meet the promised debt service payments. Hence, the default barrier is determined not only by debt principal, but also by asset volatility, debt maturity, payout rates and tax rates etc.

As a result of model variations, differences in model calibration exist. For structural models, this is particularly relevant as many key inputs are difficult to measure. Bypassing strict definitions CreditGrades is developed for immediate application, while the calibration of Leland \& Toft (1996) is more extensive. Hence, the number and characteristics of parameters to be estimated, as well as the method to infer the underlying asset value process and default barrier, differ across models.

Duarte et al. (2005) and Yu (2006) solely rely on CreditGrades calibrated with a 1000-day historical volatility. When based on a large divergence between markets, both find that capital structure arbitrage is profitable on average. At the aggregate level, the strategy appears to offer attractive Sharpe ratios and a positive average return with positive skewness. Yet, individual positions can be very risky and most 
losses occur when the arbitrageur shorts CDSs but subsequently find the market spread rapidly increasing and the equity hedge ineffective.

Due to the substantial differences in model assumptions and calibration, the key observed gap between the market and model spread fueling the arbitrageur may be driven by model misspecification. Furthermore, key inputs may be mismeasured sending the arbitrageur a false signal of relative mispricing. Hence, there is a need to understand how the risk and return vary with model choice and calibration. These caveats are unexplored in Duarte et al. (2005) and Yu (2006).

We address these two problems facing the arbitrageur, and study how the characteristics of capital structure arbitrage vary with model choice and asset volatility calibration. For this purpose, we apply the CreditGrades model and Leland \& Toft (1996). As the volatility measure is a key input to the pricing of credit, we identify relative value opportunities from a traditional 250-day historical volatility used extensively in the bond pricing literature, and a volatility measure implied from equity options.

Based on anecdotal evidence using CreditGrades, Finger \& Stamicar (2005a) and Finger \& Stamicar (2005b) show how model spreads based on historical volatilities lag the market when spreads increase, while overpredicting the market as spreads recover. However, the more responsive option-implied volatility substantially improves the pricing performance. Cremers, Driessen, Maenhout \& Weinbaum (2006) and Cao, Yu \& Zhong (2006) analyze the information content of equity options for corporate bond and CDS pricing. They find the forward-looking option-implied volatility to dominate the historical measure in explaining credit spreads, and the gain is particularly pronounced among firms with lower credit ratings. Only analyzing the determinants of credit spreads, they are silent on the risk and return of capital structure arbitrage.

As the arbitrageur feeds on large variations in credit and equity markets, these insights suggest the implied volatility to lead to superior entry and exit decisions and trading returns. Furthermore, the gain from a more timely credit signal is expected to be largest for the obligors of most interest to the arbitrageur, namely those in the speculative grade segment.

Hence, we implement the strategy on 221 North American industrial obligors in 2002 to 2004. Case studies illustrate that while model choice certainly matters in identifying relative value opportunities, the volatility input is of primary importance. The historical volatility may severely lag the market, sending the arbitrageur a false signal of relatively cheap protection in the aftermath of a crisis. The result is large losses for the arbitrageur as market spreads continue to 
tighten. Indeed, the implied volatility may result in the exact opposite positions, with obvious consequences for the arbitrageur.

However, irrespective of model choice and volatility calibration, the strategy is very risky at the level of individual obligors. Convergence may never happen and the equity hedge may be ineffective. This may force the arbitrageur to liquidate positions early and suffer large losses.

When studying the risk and return at an aggregate level, we focus on holding period returns and a capital structure arbitrage index of monthly excess returns. Both models generally result in insignificant excess returns, when calibrated with a traditional volatility from historical equity returns. However, the gain from identifying relative value opportunities from option-implied volatilities is substantial.

In a variant of the strategy based on CreditGrades, the mean holding period return for speculative grade obligors increases from 2.64 percent to 4.61 percent when implemented with option-implied volatilities. The similar numbers based on Leland \& Toft (1996) are 3.14 versus 5.47 percent. However, the incremental return is much smaller for investment grade obligors.

Additionally, the corresponding excess returns are highly significant when optionimplied volatilities are used to identify opportunities - even when small gaps are exploited. Based on CreditGrades, the mean excess return is 0.44 percent on investment grade and 1.33 percent on speculative grade obligors, both highly significant. The similar numbers when Leland \& Toft (1996) is used to identify relative value opportunities are 0.27 and 2.39 percent, both highly significant. Finally, we do not find the excess returns to represent compensation for exposure to systematic market factors.

We conclude that while model choice matters for the arbitrageur, it is second to properly measured key inputs in the calibration. Hence, if the arbitrageur relies on the dynamics of option prices when identifying relative value opportunities across equity and credit markets, the result is a substantial aggregate gain in trading returns above the benchmark application of capital structure arbitrage in Duarte et al. (2005) and $\mathrm{Yu}(2006)$.

This paper is based on the premise that structural models price CDSs reasonably well. Ericsson, Reneby \& Wang (2006) find that Leland (1994), Leland \& Toft (1996) and Fan \& Sundaresan (2000) underestimate bond spreads consistent with previous studies. However, the models perform much better in predicting CDS spreads, particularly Leland \& Toft (1996). The resulting residual CDS spreads are found to be uncorrelated with default proxies as well as non-default proxies. Furthermore, this paper is related to Schaefer \& Strebulaev (2004), who show that 
structural models produce hedge ratios of equity to debt that cannot be rejected in empirical tests.

Since the rationale for the strategy is to exploit a lack of integration between various markets, capital structure arbitrage is also related to studies on the lead-lag relationship among bond, equity and CDS markets like Hull, Predescu \& White (2004), Norden \& Weber (2004), Longstaff, Mithal \& Neis (2005) and Blanco, Brennan \& Marsh (2005). While the CDS is found to lead the bond market, no definitive lead-lag relationship exists between equity and CDS markets.

Finally, Hogan, Jarrow, Teo \& Warachka (2004) study statistical arbitrages, while Mitchell \& Pulvino (2001) and Mitchell, Pulvino \& Stafford (2002) are important studies on merger and equity arbitrage. The remainder of this paper is organized as follows. Section 2 outlines the trading strategy, while the data is presented in section 3. Section 4 presents the underlying models and calibration, and section 5 illustrates some case studies. Section 6 presents the aggregate results of the strategy, and section 7 concludes.

\section{Trading Strategy}

This section describes the trading strategy underlying capital structure arbitrage. The implementation closely follows Duarte et al. (2005) and Yu (2006), to whom we refer for a more elaborate description. Since a time-series of predicted CDS spreads forms the basis of the strategy, we start with a short description of how to price a CDS.

\subsection{CDS Pricing}

A CDS is an insurance contract against credit events such as the default on a corporate bond (the reference obligation) by a specific issuer (reference entity). In case of a credit event, the seller of insurance is obligated to buy the reference obligation from the protection buyer at par. ${ }^{2}$ For this protection, the buyer pays a periodic premium to the protection seller until the maturity of the contract or the credit event, whichever comes first. There is no requirement that the protection buyer actually owns the reference obligation, in which case the CDS is used more

\footnotetext{
${ }^{2}$ In practice, there may be cash settlement or physical settlement, as well as a possible cheapest-to-deliver option embedded in the spread. However, we refrain from this complication. Credit events can include bankruptcy, failure to pay or restructuring.
} 
for speculation rather than protection. Since the accrued premium must also be paid if a credit event occurs between two payment dates, the payments fit nicely into a continuous-time framework.

First, the present value of the premium payments from a contract initated at time 0 with maturity date $T$ can be calculated as

$$
E^{Q}\left(c(0, T) \int_{0}^{T} \exp \left(-\int_{0}^{s} r_{u} d u\right) 1_{\{\tau>s\}} d s\right)
$$

where $c(0, T)$ denotes the annual premium known as the CDS spread, $r$ the risk-free interest rate, and $\tau$ the default time of the obligor. $E^{Q}$ denotes the expectation under the risk-neutral pricing measure. Assuming independence between the default time and the risk-free interest rate, this can be written as

$$
c(0, T) \int_{0}^{T} P(0, s) q_{0}(s) d s,
$$

where $P(0, s)$ is the price of a default-free zero-coupon bond with maturity $s$, and $q_{0}(s)$ is the risk-neutral survival probability of the obligor, $P(\tau>s)$, at $t=0^{3}$.

Second, the present value of the credit protection is equal to

$$
E^{Q}\left((1-R) \exp \left(-\int_{0}^{\tau} r_{u} d u\right) 1_{\{\tau<T\}}\right)
$$

where $R$ is the recovery of bond market value measured as a percentage of par in the event of default. Maintaining the assumption of independence between the default time and the risk-free interest rate and assuming a constant $R$, this can be written as

$$
-(1-R) \int_{0}^{T} P(0, s) q_{0}^{\prime}(s) d s,
$$

where $-q_{0}^{\prime}(t)=-d q_{0}(t) / d t$ is the probability density function of the default time. The CDS spread is determined such that the value of the credit default swap is zero at initiation

$$
0=c(0, T) \int_{0}^{T} P(0, s) q_{0}(s) d s+(1-R) \int_{0}^{T} P(0, s) q_{0}^{\prime}(s) d s,
$$

\footnotetext{
${ }^{3}$ Later, we focus on constant interest rates. This assumption, together with independence between the default time and the risk-free interest rate, allows us to concentrate on the relationship between the equity price and the CDS spread. This is exactly the relationship exploited in the relative value strategy.
} 
and hence

$$
c(0, T)=-\frac{(1-R) \int_{0}^{T} P(0, s) q_{0}^{\prime}(s) d s}{\int_{0}^{T} P(0, s) q_{0}(s) d s} .
$$

The preceding is the CDS spread on a newly minted contract. To calculate daily returns to the arbitrageur on open trades, the relevant issue is the value of the contract as market conditions change and the contract is subsequently held. To someone who holds a long position from time 0 to $t$, this is equal to

$$
\pi(t, T)=(c(t, T)-c(0, T)) \int_{t}^{T} P(t, s) q_{t}(s) d s
$$

where $c(t, T)$ is the CDS spread on a contract initiated at $t$ with maturity date $T$. The value of the open CDS position $\pi(t, T)$ can be interpreted as a survivalcontingent annuity maturing at date $T$, which depends on the term-structure of survival probabilities $q_{t}(s)$ through $s$ at time $t$. The survival probability $q_{t}(s)$ depends on the market value of equity $S_{t}$ through the underlying structural model, and we follow $\mathrm{Yu}(2006)$ in defining the hedge ratio $\delta_{t}$ as

$$
\delta_{t}=N * \frac{\partial \pi(t, T)}{\partial S_{t}}
$$

where $N$ is the number of shares outstanding. ${ }^{4}$ Hence, $\delta_{t}$ is defined as the dollaramount of shares bought per dollar notional in the CDS. The choice of underlying model-framework and calibration is discussed in section 4 .

\subsection{Implementation of the Strategy}

Using the market value of equity, an associated volatility measure and the liability structure of the obligor, the arbitrageur uses a structural model to gauge the richness and cheapness of the CDS spread. Comparing the daily spread observed in the market with the equity-implied spread from the model, the model helps identify credits that either offer a discount against equities or trade at a very high level.

If e.g. the market spread at a point in time has grown substantially larger than the model spread, the arbitrageur sees an opportunity. It might be that the credit

\footnotetext{
${ }^{4}$ This calculation deviates slightly from the one in $\mathrm{Yu}$ (2006), since we formulate all models on a total value basis and not per share. Equation (8) follows from a simple application of the chain rule.
} 
market is gripped by fear and the equity market is more objective. Alternatively, he might think that the equity market is slow to react and the CDS spread is priced fairly. If the first view is correct, he should sell protection and if the second view is correct, he should sell equity. Either way, the arbitrageur is counting on the normal relationship between the two markets to return. He therefore takes on both short positions and profits if the spreads converge. In the opposite case with a larger model spread, the arbitrageur buys protection and equity.

This relative value strategy is supposed to be less risky than a naked position in either market, but is of course far from a textbook definition of arbitrage. Two important caveats to the strategy are positions initiated based on model misspecification or mismeasured inputs. Such potential false signals of relative mispricing are exactly what this paper addresses.

We conduct a simulated trading exercise based on this idea across all obligors. Letting $\alpha$ be the trading trigger, $c_{t}^{\prime}$ the CDS spread observed in the market at date $t$ and $c_{t}$ short-hand notation for the equity-implied model spread, we initiate a trade each day if one of the following conditions are satisfied

$$
c_{t}^{\prime}>(1+\alpha) c_{t} \text { or } c_{t}>(1+\alpha) c_{t}^{\prime}
$$

In the first case, a CDS with a notional of $\$ 1$ and shares worth $\$-\delta_{t} * 1$ are shorted. ${ }^{5}$ In the second case, the arbitrageur buys a CDS with a notional of $\$ 1$ and buys shares worth $\$-\delta_{t} * 1$ as a hedge.

Since $\mathrm{Yu}$ (2006) finds his results insensitive to daily rebalancing of the equity position, we follow his base case and adopt a static hedging scheme. The hedge ratio in equation (8) is therefore fixed throughout the trade and based on the model CDS spread $c_{t}$ when entering the position.

Knowing when to enter positions, the arbitrageur must also decide when to liquidate. We assume that exit occurs when the spreads converge, defined as $c_{t}=c_{t}^{\prime}$, or by the end of a pre-specified holding period, which ever comes first. In principle, the obligor can also default or be acquired by another company during the holding period. Yu (2006) notes that in most cases the CDS market will reflect these events long before the actual occurrences, and the arbitrageur will have ample time to make exit decisions. ${ }^{6}$ Specifically, it is reasonable to assume

\footnotetext{
${ }^{5} \delta_{t}$ is, of course, negative.

${ }^{6}$ This argument seems to be supported in Arora, Bohn \& Zhu (2005), who study the surprise effect of distress announcements. Conditional on market information, they find only 11 percent of the distressed firms' equities and 18 percent of the distressed bonds to respond significantly. The vast majority of prices are found to reflect the credit deterioration well before the distress
} 
that the arbitrageur will be forced to close his positions once the liquidity dries up in the underlying obligor. Such incidents are bound to impose losses on the arbitrageur.

\subsection{Trading returns}

The calculation of trading returns is fundamental to analyze how the risk and return differ across model assumptions and calibration methods. Since the CDS position has a zero market value at initiation, trading returns must be calculated by assuming that the arbitrageur has a certain level of initial capital. This assumption allows us to hold fixed the effects of leverage on the analysis. The initial capital is used to finance the equity hedge, and is credited or deducted as a result of intermediate payments such as dividends or CDS premia. Each trade is equipped with this initial capital and a limited liability assumption to ensure well-defined returns. Hence, each trade can be thought of as an individual hedge fund subject to a forced liquidation when the total value of the portfolio becomes zero. ${ }^{7}$

Through the holding period the value of the equity position is straightforward, but the value of the CDS position has to be calculated using equation (7) and market CDS spreads $c^{\prime}(t, T)$ and $c^{\prime}(0, T)$. Since secondary market trading is very limited in the CDS market and not covered by our dataset, we adopt the same simplifying assumption as $\mathrm{Yu}(2006)$, and approximate $c^{\prime}(t, T)$ with $c^{\prime}(t, t+T)$. That is, we approximate a CDS contract maturing in four years and ten months, say, with a freshly issued 5-year spread. This should not pose a problem since the difference between to points on the curve is likely to be much smaller than the time-variation in spreads.

$\mathrm{Yu}(2006)$ finds his results insensitive to the exact size of transaction costs for trading CDSs. We adopt his base case, and assume a 5 percent proportional bidask spread on the CDS spread. The CDS market is likely to be the largest single source of transaction costs for the arbitrageur. We therefore ignore transaction costs on equities, which is reasonable under the static hedging scheme.

announcement.

${ }^{7}$ This is reminiscent of potential large losses when marked to market, triggering margin calls and forcing an early liquidation of positions. 


\section{Data}

Data on CDS spreads is provided by the ValuSpread database from Lombard Risk Systems, dating back to July 1999. This data is also used by Lando \& Mortensen (2005) and Berndt, Jarrow \& Kang (2006). The data consists of mid-market CDS quotes on both sovereigns and corporates, with varying maturity, restructuring clause, seniority and currency. For a given date, reference entity and contract specification, the database reports a composite CDS quote together with an intradaily standard deviation of collected quotes. The composite quote is calculated as a mid-market quote by obtaining quotes from up to 25 leading market makers. This offers a more reliable measure of the market spread than using a single source, and the standard deviation measures how representative the mid-market quote is for the overall market.

We confine ourselves to 5-year composite CDS quotes on senior unsecured debt for North American corporate obligors with currencies denominated in US dollars. Indeed, the 5-year maturity is considered the most liquid point on the credit curve. Regarding the specification of the credit event, we follow $\mathrm{Yu}$ (2006) and large parts of the literature in using contracts with a modified restructuring clause. The frequency of data on CDS quotes increases significantly through time, reflecting the growth and improved liquidity in the market. To generate a subsample of the data suitable for capital structure arbitrage, we apply several filters.

First, we merge the CDS data with quarterly balance sheet data from Compustat and daily stock market data from CRSP. The quarterly balance sheet data is lagged one month from the end of the quarter to avoid the look-ahead bias in using data not yet available in the market. We then exclude firms from the financial and utility sector.

Second, for each obligor in the sample, daily data on the 30-day at-the-money put-implied volatility is obtained from OptionMetrics. OptionMetrics is a comprehensive database of daily information on exchange-listed equity options in the U.S. since 1996. OptionMetrics generates the 30-day at-the-money put-implied volatility by interpolation.

Third, in order to conduct the simulated trading exercise, a reasonably continuous time-series of CDS quotes must be available. In addition, the composite quote must have a certain quality. Therefore, we define the relative quote dispersion as the intra-daily standard deviation of collected quotes divided by the mid-market quote. All daily mid-market quotes with an intra-daily quote dispersion of zero 
or above 40 percent are then deleted. ${ }^{8}$ For each obligor, we next search for the longest string of more than 100 daily quotes no more than 14 calender days apart, which have all information available on balance sheet variables, equity market and equity options data. ${ }^{9}$ As noted in $\mathrm{Yu}$ (2006), this should also yield the most liquid part of coverage for the obligor, forcing the arbitrageur to close his positions once the liquidity vanishes.

Finally, 5-year and 3-month constant maturity treasury yields are obtained from the Federal Reserve Bank of St. Louis. These interest rates are used to calculate the equity-implied 5-year CDS spread, and to calculate excess returns from the trading strategy.

Applying this filtration to the merged dataset results in 221 obligors with 65,476 daily composite quotes, dating back to July 2002 and onwards to the end of September 2004. Table 1 presents summary statistics for the obligors across the senior unsecured credit rating from Standard \& Poor's when entering the sample. The variables presented are averages over time and then firms. The majority of firms are BBB rated, and 16 firms are in the speculative grade segment, including one non-rated obligor. A lower spread is associated with a lower leverage and volatility, which is in line with predictions of structural credit risk models.

We implement the trading strategy using the implied volatility from equity options (IV), and a 250-day volatility from a historical time-series of equity values $(\mathrm{HV})$. On average these volatilities are similar, but it turns out that the dynamics of option prices provide the arbitrageur with superior information. The average correlation between changes in the spread and the equity value is negative as expected from a structural viewpoint, but fairly low. This is consistent with $\mathrm{Yu}$ (2006) and correlations ranging from minus 5 to minus 15 percent quoted by traders in Currie \& Morris (2002). This indicates that the two markets may drift apart and hold divergent views on obligors, which fuels the arbitrageur ex ante. Ex post, it suggests that the equity hedge may be ineffective.

\section{[Table1 about here]}

\footnotetext{
${ }^{8}$ One could argue for a cut-off point at a lower relative dispersion, but on the other hand a trader is likely to take advantage of high uncertainty in the market. The vast majority of quotes have a relative dispersion below 20 percent.

${ }^{9}$ As discussed below, this may give rise to a survivorship issue. However, we try to minimize this by requiring a string of only 100 spreads, far less than Yu (2006). In any case, this should not pose a problem, since the focus of the paper is on relative risk and return across models and calibration methods, and not absolute measures.
} 


\section{Model Choice and Volatility Calibration}

Having the trading strategy and data explained, we next introduce the two underlying models and the associated calibration. The formulas for each model including the risk-neutral survival probability $q_{t}(s)$, the CDS spread $c(0, T)$, the contract value $\pi(t, T)$ and the equity delta $\delta(t, T)$ are described in the appendix. Further details on the models can be found in Finger (2002) and Leland \& Toft (1996).

\subsection{CreditGrades}

The CreditGrades model is jointly developed by RiskMetrics, JP Morgan, Goldman Sachs and Deutsche Bank with the purpose to establish a simple framework linking credit and equity markets. As noted by Currie \& Morris (2002) and Yu (2006), this model has become an industry benchmark widely used by traders, preferably calibrated with a rolling 1000-day historical volatility as advocated in Finger (2002).

It loosely builds on Black \& Cox (1976), with default defined as the first passage time of firm assets to an unobserved default barrier. Hence, deviating from traditional structural models, it assumes that the default barrier is an unknown constant drawn from a known distribution. This element of uncertain recovery increases short-term spreads, but cannot do so consistently through time. ${ }^{10}$

Originally, the model is built on a per-share basis taking into account preferred shares and the differences between short-term versus long-term and financial versus non-financial obligations, when calculating debt per share. Like Yu (2006), we only work with total liabilities and common shares outstanding. Therefore, we formulate the model based on total liabilities and market value of equity.

Under the risk-neutral measure, the firm assets $V$ are assumed to follow

$$
d V_{t}=\sigma_{V} V_{t} d W_{t}
$$

where $\sigma_{V}$ is the asset volatility and $W_{t}$ is a standard Brownian motion. The zero drift is consistent with the observation of stationary leverage ratios in CollinDufresne \& Goldstein (2001). The default barrier is $L D$, where $L$ is a random recovery rate given default, and $D$ denotes total liabilities. The recovery rate $L$ follows a lognormal distribution with mean $\bar{L}$, interpreted as the mean global recovery rate on all liabilities, and standard deviation $\lambda$. Then, $R$ in equation (6)

\footnotetext{
${ }^{10}$ A theoretically more appealing approach is given by Duffie \& Lando (2001).
} 
is the recovery rate on the specific debt issue underlying the CDS.

Instead of working with a full formula for the value of equity $S$, CreditGrades uses the linear approximation

$$
V=S+\bar{L} D
$$

which also gives a relation between asset volatility $\sigma_{V}$ and equity volatility $\sigma_{S}$

$$
\sigma_{V}=\sigma_{S} \frac{S}{S+\bar{L} D}
$$

The model is easy to implement in practice. In particular, $D$ is the total liabilities from quarterly balance sheet data, $S$ is the market value of equity calculated as the number of shares outstanding multiplied by the closing price, and $r$ is the 5 -year constant maturity treasury yield. Furthermore, the bond-specific recovery rate $R$ is assumed to be 0.5 and the standard deviation of the global recovery rate $\lambda$ is 0.3. All parameters are motivated in Finger (2002) and Yu (2006).

The volatility measure is a key input to the pricing of credit. Instead of using a rolling 1000-day volatility $\sigma_{S}$ from historical equity values as $\mathrm{Yu}(2006)$, we implement the strategy using a 250-day historical volatility and the implied volatility from equity options. According to Cremers et al. (2006) and Cao et al. (2006), the implied volatility contains important and timely information about credit risk different from the historical measure. This may potentially lead the arbitrageur to superior entry and exit decisions and trading returns. We expect the gain to be most pronounced for the speculative grade sample, where obligors typically experience large variations in spreads. Here, historical volatilities may lag true market levels and send a false signal of mispricing to the arbitrageur.

Finally, we follow $\mathrm{Yu}$ (2006) in using the mean global recovery rate $\bar{L}$ to align the model with the credit market before conducting the trading exercise. In particular, we infer $\bar{L}$ by minimizing the sum of squared pricing errors using the first 10 CDS spreads in the sample for each firm. Now, all parameters are in place to calculate the time-series of CDS spreads underlying the analysis, together with hedge ratios and values of open CDS positions.

\subsection{Leland \& Toft (1996)}

This model assumes that the decision to default is made by a manager, who acts to maximize the value of equity. At each moment, the manager must address 
the question whether meeting promised debt service payments is optimal for the equityholders, thereby keeping their call option alive. If the asset value exceeds the endogenously derived default barrier $V_{B}$, the firm will optimally continue to service the debt - even if the asset value is below the principal value or if cash flow available for payout is insufficient to finance the net debt service, requiring additional equity contributions.

In particular, firm assets $V$ are assumed to follow a geometric Brownian motion under the risk-neutral measure

$$
d V_{t}=(r-\rho) V_{t} d t+\sigma_{V} V_{t} d W_{t}
$$

where $r$ is the constant risk-free interest rate, $\rho$ is the fraction of asset value paid out to security holders, $\sigma_{V}$ is the asset volatility and $W_{t}$ is a standard Brownian motion. Debt of constant maturity $\Upsilon$ is continuously rolled over, implying that at any time $s$ the total outstanding debt principal $P$ will have a uniform distribution over maturities in the interval $(s, s+\Upsilon)$. Each debt contract in the multi-layered structure is serviced by a continuous coupon. The resulting total coupon payments $C$ are tax deductible at a rate $\tau$, and the realized costs of financial distress amount to a fraction $\alpha$ of the value of assets in default $V_{B}$. Rolling over finite maturity debt in the way prescribed implies a stationary capital structure, where the total outstanding principal $P$, total coupon $C$, average maturity $\frac{\Upsilon}{2}$ and default barrier $V_{B}$ remain constant through time.

To determine the total value of the levered firm $v\left(V_{t}\right)$, the model follows Leland (1994) in valuing bankruptcy costs $B C\left(V_{t}\right)$ and tax benefits resulting from debt issuance $T B\left(V_{t}\right)$ as time-independent securities. It follows, that

$$
\begin{aligned}
v\left(V_{t}\right) & =V_{t}+T B\left(V_{t}\right)-B C\left(V_{t}\right) \\
& =S\left(V_{t}\right)+D\left(V_{t}\right),
\end{aligned}
$$

where $S\left(V_{t}\right)$ is the market value of equity and $D\left(V_{t}\right)$ the market value of total debt.

To implement the model, we follow Ericsson et al. (2006) in setting the realized bankruptcy cost fraction $\alpha=0.15$, the tax rate $\tau=0.20$ and the average debt maturity $\frac{\Upsilon}{2}=3.38 .^{11}$ Furthermore, as above, $P$ is the total liabilities from

\footnotetext{
${ }^{11}$ The choice of 15 percent bankruptcy costs lies well within the range estimated by Andrade \& Kaplan (1998). 20 percent as an effective tax rate is below the corporate tax rate to reflect the personal tax rate advantage of equity returns. Stohs \& Mauer (1996) find an average debt maturity of 3.38 years using a panel of 328 industrial firms with detailed debt information in Moody's Industrial Manuals in 1980-1989.
} 
quarterly balance sheet data, $S$ is the market value of equity and $r$ is the 5 -year constant maturity treasury yield. We also follow Ericsson et al. (2006) in assuming that the average coupon paid out to all debtholders equals the risk-free interest rate, $C=r P .{ }^{12}$ The asset payout rate $\rho$ is calculated as a time-series mean of the weighted average historical dividend yield and relative interest expense from balance sheet data

$$
\begin{aligned}
\rho & =\left(\frac{\text { Interest expenses }}{\text { Total liabilities }}\right) \times L+(\text { Dividend yield }) \times(1-L) \\
L & =\frac{\text { Total liabilities }}{\text { Total liabilities }+ \text { Market equity }} .
\end{aligned}
$$

Contrary to CreditGrades, the default barrier $V_{B}$ is endogenously determined and varies with fundamental characteristics of the firm such as leverage, asset volatility, debt maturity and asset payout rates. Due to the full-blown relationship between equity and assets, the estimation of the asset value $V$ and asset volatility $\sigma_{V}$ is a more troublesome exercise in Leland \& Toft (1996).

Hence, when analyzing the trading strategy with a 250-day historical volatility, we use the iterative algorithm of Moody's KMV outlined in Crosbie \& Bohn (2003) and Vassalou \& Xing (2004) to infer the unobserved time-series of asset values and asset volatility. This iterative algorithm is preferable over an instantaneous relationship between asset volatility $\sigma_{V}$ and equity volatility $\sigma_{S}$, governed by Ito's lemma. The latter underlies the implementation of CreditGrades in equation (12), and is used in Jones, Mason \& Rosenfeld (1984). As noted in Lando (2004), the iterative algorithm is particularly preferable when changes in leverage are significant over the estimation period.

In short, the iterative scheme goes as follows. The market value of equity $S_{t}$ is a function of a parameter vector $\theta$, the asset value $V_{t}$, default barrier $V_{B}\left(\sigma_{V}\right)$ and asset volatility $\sigma_{V}, S_{t}=f\left(V_{t}, \sigma_{V}, \theta\right)$. Using quarterly balance sheet data, a rolling 250-day window of historical equity values and an initial guess of the asset volatility, we calculate the default barrier and invert the equity pricing formula to infer an implied time-series of asset values $V_{t}\left(\sigma_{V}\right)=f^{-1}\left(S_{t}, \sigma_{V}, \theta\right)$. The market value of assets follow a geometric Brownian motion, allowing us to obtain an updated asset volatility and default barrier. This procedure is repeated until the values of $\sigma_{V}$ converge.

\footnotetext{
${ }^{12}$ A firm's debt consists of more than market bonds, and usually a substantial fraction of total debt is non-interest bearing such as accrued taxes and supplier credits. Furthermore, corporate bonds may be issued below par, which also opens up for this approximation.
} 
When analyzing the trading exercise based on implied volatilities from equity options, we do not face the problem of changing leverage in a historical estimation window. Therefore, we solve the instantaneous relationship

$$
\begin{gathered}
S_{t}=f\left(V_{t}, \sigma_{V}, \theta\right) \\
\sigma_{S}=\frac{\partial S_{t}}{\partial V_{t}} \sigma_{V} \frac{V_{t}}{S_{t}}
\end{gathered}
$$

numerically for the unknown asset value $V_{t}$ and asset volatility $\sigma_{V}$.

Before conducting the trading exercise, we now use the bond-specific recovery rate $R$ to align the model with the market spreads. This is done since the default barrier is endogenously determined. For this purpose, we again use the first 10 CDS spreads in the sample for each firm. As noted in Yu (2006), the bond-specific recovery rate is also the free parameter used in practice by traders to fit the level of market spreads.

\subsection{Model Calibration and Implied Parameters}

Table 2 presents summary statistics of implied parameters from CreditGrades and Leland \& Toft (1996), using a rolling 250-day historical volatility (HV) and implied volatility (IV). The table also shows average calibration targets from the equity and equity options market, together with asset payout rates. In CreditGrades implemented with a historical volatility in panel $A$, the average market value of assets $V$ is $\$ 20,592$ million with a median of $\$ 14,839$ million, while the average and median expected default barrier $\bar{L} D$ is $\$ 8,556$ million and $\$ 3,846$ million, respectively. The mean asset volatility $\sigma_{V}$ is 22.8 percent, with a median of 21.3 percent. Finally, the average and median mean global recovery rate $\bar{L}$ is 0.799 and 0.573 , respectively. Similar implied parameters result on aggregate when implemented with the implied volatility in panel B.

[Table 2 about here]

When implementing Leland \& Toft (1996) in panel C and D, several differences from CreditGrades are apparent. First, the asset values appear larger and asset volatilities lower. This is due to the observation that the relatively high endogenous default barrier $V_{B}$ increases the theoretical equity volatility, ceteris paribus. Hence, the model implies a higher asset value and/or lower asset volatility in order to match the theoretical and observed equity volatility. 
Second, the variation in implied bond recovery $R$ across the two volatility measures is large. Based on the historical volatility, both the average and median implied bond recovery are highly negative, indicating that the model underestimates the level of market spreads in the beginning of the sample period. ${ }^{13}$ Implied recoveries are more plausible when inferred from option-implied volatilities. Although the mean continues to be negative, the median is 0.233 . This is indicative of an implied volatility that varies stronger with changes in the CDS spread. Indeed, calculating the mean correlation between changes in CDS spreads and changes in volatility measures, the correlation is 1.8 and 9.9 percent based on historical and implied volatilities, respectively.

The variation in implied mean global recovery $\bar{L}$ in CreditGrades is much smaller across volatility measures. This is a manifestation of the difference in information used at various stages, when calibrating the two models. In CreditGrades the expected default barrier is exogenous, while it is endogenously determined in Leland \& Toft (1996). As a result of the linear approximation in equation (11), asset values, the asset volatility and the expected default barrier are not nailed down and determined in CreditGrades until the mean global recovery rate is inferred from the initial CDS spreads. Subsequent to nailing down this key parameter, there is a one-to-one relationship between changes in equity and assets, $\frac{\partial S}{\partial V}=1$.

The default mechanism in Leland \& Toft (1996) implies a different use of market data. Here, the asset value and asset volatility are solely determined from the equity and equity options market. Together with the endogenous default barrier, this gives far less flexibility when fitting the final bond recovery from initial CDS spreads. The result is more extreme values for this parameter. ${ }^{14}$ However, the subsequent relationship and wedge between equity and assets vary with the distance to default. When close to default, $\frac{\partial S}{\partial V}$ is very steep and below one. Although delta may go above one as the credit quality improves, the relationship approaches one-to-one when far from default. Hence, the variation in asset dynamics across the two models may be substantial for speculative grade obligors, with direct consequences for the arbitrageur.

\footnotetext{
${ }^{13}$ This should not be a problem for the current trading strategy, since subsequent movements in relative prices across equity and credit markets drive the arbitrageur, not absolute levels. The most extreme bond recovery of $-1,858$ results from an underestimation of only 50 bps. In this case, the market spread is close to $50 \mathrm{bps}$, while the model spread with a reasonable bond recovery is close to zero.

${ }^{14}$ If CreditGrades is implemented with a mean global recovery of 0.5 as suggested in Finger (2002), we qualitatively get the same results for the implied bond recovery as in Leland \& Toft (1996).
} 
From the discussion in section 2, the chosen structural model plays a central role in all parts of capital structure arbitrage. In particular, the model underlies the term-structure of survival probabilities, equity-implied CDS spreads, hedge ratios, the valuation of open CDS positions and trading returns. As shown above, assumptions behind CreditGrades and Leland \& Toft (1996), as well as practical implementation, vary substantially. How these differences in model choice and calibration manifest in profitability and strategy execution is analyzed next. Before turning to the general results across all obligors, some case studies are analyzed.

\section{Case Studies}

In this section, the two models calibrated with historical and option-implied volatilities are used to identify divergent views in equity and credit markets. The case studies illustrate that while model choice certainly matters in identifying relative value opportunities, the volatility input is of primary importance. In fact, the two volatility measures may result in opposite positions, with obvious consequences for the arbitrageur. The final study illustrates that the strategy is very risky at the level of individual obligors.

\subsection{Sears, Roebuck and Company}

Figure 1 illustrates the fundamentals of capital structure arbitrage for the large retailer Sears, Roebuck and Company, rated A by S\&P and Baa1 by Moody's. Panel A and B depict the equity-implied model spreads and CDS spreads observed in the market from September 2002 to June 2004 (excluding the initial 10 spreads reserved for calibration), while panel $\mathrm{C}$ and $\mathrm{D}$ depict equity volatilities and the market value of equity, respectively.

The uncertainty in the markets increases substantially in the beginning of the period. Moody's changes their rating outlook to negative on October 18 2002, due to increasing uncertainty in the credit card business and management changes. In this period, equity prices tumble and CDS spreads reach 379 bps on October 24 2002, a doubling in 2 weeks. While the markets begin to recover shortly thereafter, model spreads based on the sticky historical volatility continue far into 2003 to suggest the arbitrageur to buy protection and buy equity as a hedge. However, with only few exceptions the market spreads tighten in the succeeding period, and the market and model spreads never converge. Depending on the size of the trading trigger and the chosen model, many losing CDS positions are initiated 
although partially offset by an increasing equity price.

Panel C illustrates how the historical volatility severely lags the more timely implied volatility, sending the arbitrageur a false signal of relatively cheap protection in the aftermath of the crisis. In fact, spreads inferred from implied volatilities quickly tighten and may initiate the exact opposite strategy. Using this volatility, spreads in Leland \& Toft (1996) indicate that protection is trading too expensive relative to equity from the end of 2002. Indeed, selling protection and selling equity as hedge result in trading returns of 5 to 15 percent on each daily position due to tightening market spreads and convergence on June 5, 2003. Subsequent to convergence, implied volatilities suggest the equity and credit markets to move in tandem and hold similar views on the credit outlooks.

As a final observation, model spreads in CreditGrades react stronger to changes in volatility than Leland \& Toft (1996), widening to over 1000 bps as the implied volatility from equity options peaks. This may be due to the endogenous default barrier in the latter model. Indeed, increasing the asset volatility causes equityholders to optimally default later in Leland \& Toft (1996). This mitigates the effect on the spread.

[Figure 1 about here]

\subsection{Time Warner and Motorola}

Simulating the trading strategy on Time Warner and Motorola supports the former insights. Figure 2 depicts the fundamentals behind Time Warner, rated BBB by S\&P and Baa1 by Moody's. In August 2002 just prior to the beginning of the sample, Moody's changes their outlook to negative as the SEC investigates the accounting practices and internal controls. As markets recover in late 2002, CreditGrades with historical volatility indicates that protection is cheap relative to equity, while spreads in Leland \& Toft (1996) are more neutral. Although equity prices increase throughout 2003, many losing trades are initiated as market spreads are more than cut by half within few months and Moody's changes their outlook back to stable.

Again, the historical volatility lags the market following the episode, while the implied volatility is more responsive. In October and November 2002, where market spreads have already tightened substantially, model spreads inferred from implied volatilities suggest that protection is expensive relative to equity and should tighten further. Selling protection at 339 bps and equity at $\$ 14.75$ on October 31,2002 , result in convergence and 15 percent returns on December 12, where the 
CDS and equity are trading at 259 bps and $\$ 13.56$, respectively. However, spreads inferred from implied volatilities are volatile, resulting in rather noisy estimates of credit outlooks and a frequent liquidation of positions as market spreads tighten. Operating with a very low trigger may reverse positions several times during this period, while a trigger of 0.5 results in only few positions.

In figure 3, the key variables for Motorola, rated BBB by $\mathrm{S} \& \mathrm{P}$, are depicted. Building on historical volatilities, the arbitrageur initiates many trades and suffers losses, while implied volatilities suggest the two markets to move in tandem and hold similar views on the obligor. In the latter case, only few relative value opportunities are apparent.

[Figure 2 and 3 about here]

\subsection{Mandalay Resort Group}

Capital structure arbitrage is very risky when based on individual obligors, and the arbitrageur may end up in severe problems irrespective of model choice and calibration. Figure 4 presents the fundamental variables behind Mandalay Resort Group, rated BB by S\&P. Throughout the coverage, spreads in Leland \& Toft (1996) based on historical volatilities diverge from market spreads in a smooth manner, while spreads in CreditGrades diverge more slowly. In both cases, the arbitrageur sells protection and equity as hedge but suffers losses as positions are liquidated after the maximum holding period.

Based on implied volatilities, May and June 2004 are particularly painful as model spreads plunge and stay tight throughout the coverage. On June 4, 2004 the competitor MGM Mirage announces a bid to acquire Mandalay Resort Group for $\$ 68$ per share plus assumption of Mandalay's existing debt. Moody's places the rating on review for a possible downgrade, due to a high level of uncertainty regarding the level of debt employed to finance the takeover. As a result, the equity price increases from $\$ 54$ to $\$ 69$ over a short period, the implied volatility plunges and the CDS spread widens from 188 bps to 227 bps. ${ }^{15}$ On June 15, 2004 a revised offer of $\$ 71$ per share is approved, and the transaction is completed on April 26, 2005.

This opposite reaction in equity and credit gives the arbitrageur short in both markets a painful one-two punch similar to the one experienced by hedge funds

\footnotetext{
${ }^{15}$ Implied volatilities from at-the-money calls plunge as well.
} 
in May 2005, where General Motors is downgraded while the equity price soars. ${ }^{16}$ Luckily, not many trades are open during the takeover bid as model and market spreads recently converged. However, the short positions initiated in May 2004, where credit seems expensive relative to equity, suffer large losses on both legs.

[Figure 4 about here]

\section{General Results}

In this section, we simulate the trading strategy for all 221 obligors. Following $\mathrm{Yu}$ (2006), we assume an initial capital of $\$ 0.5$ for each trade and $\$ 1$ notional in the CDS. The strategy is implemented for trading triggers $\alpha$ of 0.5 and 2 , and maximum holding periods of 30 and 180 days.

Naturally, absolute trading returns will vary with the above characteristics, as well as the particular period studied and how to account for vanishing liquidity etc. However, these characteristics are all fixed when studying the relative risk and return across models and calibration methods. Therefore, a scaling of returns with the amount of initial capital is unlikely to influence our conclusions. ${ }^{17}$ Indeed, although based on a different dataset, the benchmark results for CreditGrades with a historical volatility are similar to the findings in $\mathrm{Yu}$ (2006).

Table 3 and 4 present the summary statistics of holding period returns based on CreditGrades and Leland \& Toft (1996), respectively. A longer maximum holding period leads to more converging trades, fewer trades with negative returns and higher average returns. This fundamental result underlies both models and volatility measures. Consistent with Yu (2006), although the distribution of returns becomes less dispersed, a higher trading trigger does not necessarily lead to higher mean returns.

When identifying relative value opportunities from implied not historical volatilities, the number of initiated trades rises for investment grade obligors and falls for speculative grade obligors. This results from both models, although the absolute number of trades is larger in Leland \& Toft (1996). This is consistent with findings in Finger \& Stamicar (2005a) and Cao et al. (2006), where the advantage of implied volatility in tracking market spreads with CreditGrades is concentrated

\footnotetext{
${ }^{16}$ This case study is discussed in Duarte et al. (2005).

${ }^{17} \mathrm{Yu}$ (2006) also conducts his analysis with an initial capital of $\$ 0.1$. The resulting returns are scaled up accordingly. Unreported results with this initial capital and other trading triggers leave our conclusions unchanged.
} 
among speculative grade obligors. We find this measure to identify fewer relative value opportunities on obligors with larger variations in spreads.

The results clearly show a difference in risk and return across models and volatility input. Identifying relative value opportunities on speculative grade obligors in CreditGrades with a historical volatility, a maximum holding period of 180 days and a trading trigger of 2 yields a mean holding period return of 2.64 percent. However, simulating the trading strategy with option-implied volatilities increases the return to 4.61 percent. ${ }^{18}$ The corresponding numbers based on Leland \& Toft (1996) are 3.14 and 5.47 percent. The gain from implied volatilities across trading triggers and maximum holding periods is also apparent from the number of trades ending in convergence and the fraction of trades with negative returns. However, the incremental return is much smaller for investment grade obligors.

On top of this, the mean holding period return and dispersion are both higher on speculative grade obligors compared to the investment grade sample. This supports the similar result in $\mathrm{Yu}$ (2006) and happens irrespective of model choice and volatility measure. Although more likely to suffer from vanishing liquidity and default, this supports his observation that the aggregate success of the strategy depends on the availability of large variations in spreads. For such obligors, the more timely implied volatility results in incremental trading returns from superior entry and exit decisions.

The holding period returns are more favorable when Leland \& Toft (1996) is used to identify relative value opportunities. However, in practice it is hard to discern exactly where the difference arises, as the models differ in many respects and enter in all parts of the strategy. While model choice does matter, it seems second to properly measured key inputs.

[Table 3 and 4 about here]

\subsection{Capital Structure Arbitrage Index Returns}

As illustrated in the previous sections, capital structure arbitrage is very risky at the level of individual trades. The hedge may be ineffective and the markets may continue to diverge, resulting in losses and potential early liquidations. However, when initiated on the cross-section of obligors, the strategy may be profitable

\footnotetext{
${ }^{18}$ While the average profitability increases when identifying relative value opportunities from implied volatilities, so does the volatility of returns. As the mean holding period return consists of many overlapping holding periods, the statistical significance of trading returns is analyzed from a return index below.
} 
on average depending on the particular implementation. Having established this finding, the next step is to understand the sources of the profits, i.e. whether the returns are correlated with priced systematic risk factors. Hence, we construct a monthly capital structure arbitrage excess return index from all individual trades, following Duarte et al. (2005) and Yu (2006).

Specifically, we compute daily excess returns for all individual trades over the entire holding period. On a given day, thousands of trades may be open. By essentially assuming that the arbitrageur is always invested in an equally-weighted portfolio of hedge funds, where each fund consists of one trade, we calculate an equally-weighted average of the excess returns on a daily basis. These average daily excess returns are then compounded into a monthly frequency.

Table 5 presents the summary statistics of monthly excess returns based on a maximum holding period of 180 days, covering 24 months in 2002-2004. However, some strategies result in months with no trades. In this case, a zero excess return is assumed.

Again, although also present in the investment grade segment, the benefit of option-implied volatilities is concentrated among speculative grade obligors. Additionally, timely inputs are relatively more important than the exact structural model underlying the strategy. In particular, when based on CreditGrades with option-implied volatilities and a trading trigger of 2 , the mean excess return is 0.44 percent on investment grade and 1.33 percent on speculative grade obligors. These numbers are highly significant after correcting for serial correlation. The corresponding numbers when Leland \& Toft (1996) is used to identify relative value opportunities are 0.27 and 2.39 percent, respectively, both highly significant.

The excess returns resulting from a historical volatility are much smaller and most often insignificant. Indeed, the mean excess return from this measure may turn negative and significant at a lower trading trigger of 0.5 , while it continues to be positive and significant based on implied volatilities.

Addressing whether fixed income arbitrage is comparable to picking up nickels in front of a steamroller, Duarte et al. (2005) find that most of the strategies result in monthly excess returns that are positively skewed. While our results are mixed when relative value positions are identified from historical volatilities, the skewness is always positive when based on the implied measure. Thus, while producing large negative returns from time to time, this strategy tends to generate even larger offsetting positive returns.

[Table 5 about here] 
As a final exercise, we explore whether the excess returns represent compensation for exposure to systematic market factors. ${ }^{19}$ In particular, we use the excess return on the S\&P Industrial Index (S\&PINDS) to proxy for equity market risk. To proxy for investment grade and speculative grade bond market risk, the excess returns on the Lehman Brothers Baa and Ba Intermediate Index (LHIBAAI) and (LHHYBBI), respectively, are used. These variables are obtained from Datastream. As argued by Duarte et al. (2005), such market factors are also likely to be sensitive to major financial events such as a sudden flight-to-quality or flightto-liquidity. As this risk would be compensated in the excess returns from these portfolios, we may be able to control for the component of returns that is compensation for bearing the risk of major, but not yet realized, financial events.

As the CDS market was rather illiquid before mid-2002, the regressions consist of no more than 24 monthly excess returns. Hence, the results must be interpreted with caution. $\mathrm{Yu}$ (2006) finds no relationship between capital structure arbitrage monthly excess returns and any of the factors, and the factors cannot bid away the alphas (regression intercepts) of the strategy. Our $R^{2}$ range from 8 to 35 percent, but the market factors are either insignificant or only weakly significant. Surprisingly, the occasional weak significance is not related to the size and significance of excess returns, nor rating category. Hence, the evidence does not indicate that the excess returns represent compensation for exposure to factors proxying equity and bond market risk.

As we only have 24 monthly excess returns, there is little chance of detecting significant alphas after controlling for the market risk. However, the structure of excess returns after a risk-adjustment is similar to the structure of raw excess returns in table 5. Indeed, the largest difference in alphas across the historical and option-implied volatility is in the speculative grade segment. While three of four intercepts are negative based on the investment grade obligors, it is always positive on speculative grade obligors.

[Table 6 about here]

\section{Conclusion}

This paper conducts a comprehensive analysis of the risk and return of capital structure arbitrage using alternative structural credit risk models and volatility

\footnotetext{
${ }^{19}$ For brevity, only regressions with a trading trigger of 2 are reported. Similar results are obtained at a lower threshold of 0.5 .
} 
measures. Studying 221 North American industrial obligors in 2002 to 2004, a divergence between equity and credit markets initiates a convergence-based marketneutral trading strategy. However, an observed difference in market and equityimplied model CDS spread may be driven by model misspecification and key inputs may be mismeasured, sending a false signal of mispricing in the market. These caveats constitute the focal point in the study.

As the arbitrageur feeds on large variations in equity and credit markets and the asset volatility is a key input to the pricing of credit, a timely volatility measure is desirable. In such markets, the historical volatility may severely lag the market, suggesting the arbitrageur to enter into unfortunate positions and face large losses.

Using an option-implied volatility results in superior strategy execution and may initiate the opposite positions of the historical measure. The result is more positions ending in convergence, more positions with positive holding-period returns and highly significant excess returns. The gain in returns is largest for the speculative grade obligors, and cannot be explained by well-known equity and bond market factors. At a low threshold for strategy initiation, the excess return may turn negative and significant based on the historical measure, while it continues to be positive and significant based on implied volatilities.

Duarte et al. (2005) and Yu (2006) conduct the first analysis of the strategy by implementing the industry benchmark CreditGrades with a historical volatility, as reputed used by most professionals. CreditGrades and the Leland \& Toft (1996) model differ extensively in assumptions governing default and calibration method. However, while model choice certainly matters, the exact model underlying the strategy is of secondary importance.

While profitable on an aggregate level, individual trades can be very risky. Irrespective of model choice and volatility measure, the market and equity-implied model spread may continue to drift apart, and the equity hedge may be ineffective. This may force the arbitrageur to liquidate individual positions early, and suffer large losses.

A structural model allows for numerous implementations of capital structure arbitrage, as it links firm fundamentals with equities, equity options, corporate bonds and credit derivatives. As we often find the hedge in cash equities ineffective, a further improvement may lie in offsetting positions in equity options such as outof-the-money puts. This non-linear product may also reduce the gamma risk of the strategy, which can cause losses in a fast moving market. As CDS data continues to expand, future research will shed light on many unexplored properties of relative value trading across equity and credit markets. 


\section{A Appendix}

The appendix contains formulas for the risk-neutral survival probability $q_{t}(s)$, the CDS spread $c(0, T)$, the contract value $\pi(t, T)$ and the equity delta $\delta_{t}$. Both models assume constant default-free interest rates, which allow us to concentrate on the relationship between the equity price and CDS spread, also exploited in the relative value strategy.

\section{A.1 CreditGrades}

The default barrier is given by

$$
L D=\bar{L} D e^{\lambda Z-\lambda^{2} / 2}
$$

where $L$ is the random recovery rate given default, $\bar{L}=E(L), Z$ is a standard normal random variable and $\lambda^{2}=\operatorname{Var}(\ln L)$. Finger (2002) provides an approximate solution to the survival probability using a time-shifted Brownian motion, which yields the following result ${ }^{20}$

$$
q(t)=\Phi\left(-\frac{A_{t}}{2}+\frac{\ln d}{A_{t}}\right)-d \cdot \Phi\left(-\frac{A_{t}}{2}-\frac{\ln d}{A_{t}}\right)
$$

where $\Phi(\cdot)$ is the cumulative normal distribution function and

$$
\begin{aligned}
d & =\frac{V_{0}}{\bar{L} D} e^{\lambda^{2}}, \\
A_{t}^{2} & =\sigma_{V}^{2} t+\lambda^{2} .
\end{aligned}
$$

\section{A.1.1 The CDS Spread and Hedge Ratio}

Assuming constant interest rates, the CDS spread for maturity $T$ is found by inserting the survival probability (19) in equation (6), yielding

$$
c(0, T)=r(1-R) \frac{1-q(0)+H(T)}{q(0)-q(T) e^{-r T}-H(T)},
$$

\footnotetext{
${ }^{20}$ In essence, the uncertainty in the default barrier is shifted to the starting value of the Brownian motion. In particular, the approximation assumes that $W_{t}$ starts at an earlier time than $t=0$. As a result, the default probability is non-zero for even very small $t$, including $t=0$. In other models such as Leland \& Toft (1996), the survival probability $q(0)=1$.
} 
where

$$
\begin{aligned}
H(T) & =e^{r \xi}(G(T+\xi)-G(\xi)) \\
G(T) & =d^{z+1 / 2} \Phi\left(-\frac{\ln d}{\sigma_{V} \sqrt{T}}-z \sigma_{V} \sqrt{T}\right)+d^{-z+1 / 2} \Phi\left(\frac{\ln d}{\sigma_{V} \sqrt{T}}+z \sigma_{V} \sqrt{T}\right) \\
\xi & =\frac{\lambda^{2}}{\sigma_{V}^{2}} \\
z & =\sqrt{\frac{1}{4}+\frac{2 r}{\sigma_{V}^{2}}}
\end{aligned}
$$

and $G(T)$ is given in Reiner \& Rubinstein (1991).

When determining the hedge ratio, we follow Yu (2006) and approximate the contract value in equation (7) by

$$
\begin{aligned}
\pi(0, T) & =(c(0, T)-c) \int_{0}^{T} e^{-r s} q(s) d s \\
& =\frac{c(0, T)-c}{r}\left(q(0)-q(T) e^{-r T}-H(T)\right),
\end{aligned}
$$

where $c(0, T)$ is a function of the value of equity $S$ in equation (22), and $c$ is the CDS spread at initiation. ${ }^{21}$

Using equation (8) and the product rule, the hedge ratio is found as

$$
\delta_{0}=N * \frac{d \pi(0, T)}{d S}=\frac{N}{r} \frac{\partial c(0, T)}{\partial S}\left(q(0)-q(T) e^{-r T}-H(T)\right)
$$

where $N$ denotes the number of shares outstanding. The second term in the product rule is zero, since by definition $c$ is numerically equal to $c(0, T)$, evaluated at the equity value $S$. Finally, $\frac{\partial c(0, T)}{\partial S}$ is found numerically.

\section{A.2 Leland \& Toft (1996)}

Equation (14) may be written as

$$
v\left(V_{t}\right)=V_{t}+\tau \frac{C}{r}\left(1-\left(\frac{V_{t}}{V_{B}}\right)^{-x}\right)-\alpha V_{B}\left(\frac{V_{t}}{V_{B}}\right)^{-x},
$$

\footnotetext{
${ }^{21} \mathrm{Yu}(2006)$ interprets this equation in his appendix. Equation (27) represents the value of a contract entered into one instant ago at spread $c$, that now has a quoted spread of $c(0, T)$ due to a change in the value of equity.
} 
with the value of debt $D\left(V_{t}\right)$

$$
D\left(V_{t}\right)=\frac{C}{r}+\left(P-\frac{C}{r}\right)\left(\frac{1-e^{r \Upsilon}}{r \Upsilon}-I(\Upsilon)\right)+\left((1-\alpha) V_{B}-\frac{C}{r}\right) J(\Upsilon)
$$

and equity $S\left(V_{t}\right)$

$$
\begin{aligned}
S\left(V_{t}\right) & =V_{t}+\tau \frac{C}{r}\left(1-\left(\frac{V_{t}}{V_{B}}\right)^{-x}\right)-\alpha V_{B}\left(\frac{V_{t}}{V_{B}}\right)^{-x} \\
& -\frac{C}{r}-\left(P-\frac{C}{r}\right)\left(\frac{1-e^{r \Upsilon}}{r \Upsilon}-I(\Upsilon)\right) \\
& -\left((1-\alpha) V_{B}-\frac{C}{r}\right) J(\Upsilon),
\end{aligned}
$$

and default barrier $V_{B}$

$$
V_{B}=\frac{\frac{C}{r}\left(\frac{A}{r \Upsilon}-B\right)-\frac{A P}{r \Upsilon}-\frac{\tau C x}{r}}{1+\alpha x-(1-\alpha) B} .
$$

The components of the above formulae are

$$
\begin{aligned}
& A= 2 a e^{-r \Upsilon} \Phi\left(a \sigma_{V} \sqrt{\Upsilon}\right)-2 z \Phi\left(z \sigma_{V} \sqrt{\Upsilon}\right) \\
&-\frac{2}{\sigma_{V} \sqrt{\Upsilon}} \phi\left(z \sigma_{V} \sqrt{\Upsilon}\right)+\frac{2 e^{-r \Upsilon}}{\sigma_{V} \sqrt{\Upsilon}} \phi\left(a \sigma_{V} \sqrt{\Upsilon}\right)+(z-a), \\
& B=-\left(2 z+\frac{2}{z \sigma_{V}^{2} \Upsilon}\right) \Phi\left(z \sigma_{V} \sqrt{\Upsilon}\right) \\
&-\frac{2}{\sigma_{V} \sqrt{\Upsilon}} \phi\left(z \sigma_{V} \sqrt{\Upsilon}\right)+(z-a)+\frac{1}{z \sigma_{V}^{2} \Upsilon} \\
& I(\Upsilon)= \frac{1}{r \Upsilon}\left(K(\Upsilon)-e^{-r \Upsilon} F(\Upsilon)\right) \\
& K(\Upsilon)=\left(\frac{V}{V_{B}}\right)^{-a+z} \Phi\left(j_{1}(\Upsilon)\right)+\left(\frac{V}{V_{B}}\right)^{-a-z} \Phi\left(j_{2}(\Upsilon)\right), \\
& F(\Upsilon)=\Phi\left(h_{1}(\Upsilon)\right)+\left(\frac{V}{V_{B}}\right)^{-2 a} \Phi\left(h_{2}(\Upsilon)\right),
\end{aligned}
$$




$$
\begin{aligned}
J(\Upsilon)= & \frac{1}{z \sigma_{V} \sqrt{\Upsilon}}\left(-\left(\frac{V}{V_{B}}\right)^{-a+z} \Phi\left(j_{1}(\Upsilon)\right) j_{1}(\Upsilon)\right. \\
& \left.+\left(\frac{V}{V_{B}}\right)^{-a-z} \Phi\left(j_{2}(\Upsilon)\right) j_{2}(\Upsilon)\right), \\
j_{1}(\Upsilon)= & \frac{\left(-b-z \sigma_{V}^{2} \Upsilon\right)}{\sigma_{V} \sqrt{\Upsilon}} ; j_{2}(\Upsilon)=\frac{\left(-b+z \sigma_{V}^{2} \Upsilon\right)}{\sigma_{V} \sqrt{\Upsilon}}, \\
h_{1}(\Upsilon)= & \frac{\left(-b-a \sigma_{V}^{2} \Upsilon\right)}{\sigma_{V} \sqrt{\Upsilon}} ; h_{2}(\Upsilon)=\frac{\left(-b+a \sigma_{V}^{2} \Upsilon\right)}{\sigma_{V} \sqrt{\Upsilon}}, \\
a= & \frac{\left(r-\rho-\left(\sigma_{V}^{2} / 2\right)\right)}{\sigma_{V}^{2}}, \\
b= & \ln \left(\frac{V_{t}}{V_{B}}\right) \\
z= & \sqrt{\left(\left(a \sigma_{V}^{2}\right)^{2}+2 r \sigma_{V}^{2}\right)} \\
x= & a+z .
\end{aligned}
$$

$\phi(\cdot)$ and $\Phi(\cdot)$ denote the density of the standard normal distribution and the cumulative distribution function, respectively.

\section{A.2.1 The CDS Spread and Hedge Ratio}

Using equation (37), the risk-neutral survival probability at horizon $t$ is

$$
\begin{aligned}
q(t) & =1-F(t) \\
& =1-\left(\Phi\left(h_{1}(t)\right)+\left(\frac{V}{V_{B}}\right)^{-2 a} \Phi\left(h_{2}(t)\right)\right) .
\end{aligned}
$$

Assuming constant interest rates, the CDS spread for maturity $T$ is found by inserting the survival probability (45) in equation (6), yielding

$$
0=c(0, T) \int_{0}^{T} e^{-r s} q(s) d s+(1-R) \int_{0}^{T} e^{-r s} q^{\prime}(s) d s .
$$

Integrating the first term by parts, yields

$$
0=\frac{c(0, T)}{r}\left(1-e^{-r T} q(T)+\int_{0}^{T} e^{-r s} q^{\prime}(s) d s\right)+(1-R) \int_{0}^{T} e^{-r s} q^{\prime}(s) d s
$$


where the integral $-\int_{0}^{T} e^{-r s} q^{\prime}(s) d s$ is given by $K(T)$ in equation (36), following Reiner \& Rubinstein (1991). Then,

$$
0=\frac{c(0, T)}{r}\left(1-e^{-r T} q(T)\right)-\left(\frac{c(0, T)}{r}+(1-R)\right) K(T)
$$

which allows us to obtain a closed-form solution for the CDS spread

$$
c(0, T)=r(1-R) \frac{K(T)}{\left(1-e^{-r T} q(T)-K(T)\right)} .
$$

When determining the hedge ratio, we again follow Yu (2006) and approximate the contract value in equation (7) by

$$
\begin{aligned}
\pi(0, T) & =(c(0, T)-c) \int_{0}^{T} e^{-r s} q(s) d s . \\
& =\frac{c(0, T)-c}{r}\left(1-e^{-r T} q(T)-K(T)\right),
\end{aligned}
$$

where $c(0, T)$ is a function of the value of equity $S$, and $c$ is the CDS spread at initiation.

Similar to CreditGrades, the hedge ratio is found using equation (8)

$$
\delta_{0}=\frac{N}{r} \frac{\partial c(0, T)}{\partial S}\left(1-e^{-r T} q(T)-K(T)\right)
$$

However, in Leland \& Toft (1996) the CDS spread is not an explicit function of the equity value. Therefore, $\frac{\partial c(0, T)}{\partial S}$ is found numerically using

$$
\frac{\partial c(0, T)}{\partial S}=\frac{\partial c(0, T)}{\partial V} \frac{\partial V}{\partial S}=\frac{\partial c(0, T)}{\partial V} \frac{1}{\frac{\partial S}{\partial V}}
$$




\section{References}

Andrade, G. \& Kaplan, S. (1998), 'How costly is financial (not economic) distress? evidence from highly levered transactions that became distressed', The Journal of Finance 53(5), 1443-1493.

Arora, N., Bohn, J. \& Zhu, F. (2005), 'Surprise in distress announcements: Evidence from equity and bond markets', Working Paper, Moody's KMV.

Berndt, A., Jarrow, R. \& Kang, C. (2006), 'Restructuring risk in credit default swaps: An empirical analysis', Working Paper, Carnegie Mellon and Cornell University .

Black, F. \& Cox, J. C. (1976), 'Valuing corporate securities: Some effects of bond indenture provisions', The Journal of Finance 31(2), 351-367.

Blanco, R., Brennan, S. \& Marsh, I. W. (2005), 'An empirical analysis of the dynamic relation between investment-grade bonds and credit default swaps', The Journal of Finance 60(5), 2255-2281.

Cao, C., Yu, F. \& Zhong, Z. (2006), 'The information content of option-implied volatility for credit default swap valuation', Working Paper, Penn State and UC Irvine .

Collin-Dufresne, P. \& Goldstein, R. (2001), 'Do credit spreads reflect stationary leverage ratios?', Journal of Finance 56, 1929-1957.

Cremers, M., Driessen, J., Maenhout, P. \& Weinbaum, D. (2006), 'Individual stock-option prices and credit spreads', Working Paper, University of Amsterdam .

Crosbie, P. \& Bohn, J. (2003), 'Modeling default risk', Moody's KMV, (available at www.defaultrisk.com) .

Currie, A. \& Morris, J. (2002), 'And now for capital structure arbitrage', Euromoney (December), 38-43.

Duarte, J., Longstaff, F. A. \& Yu, F. (2005), 'Risk and return in fixed income arbitrage: Nickels in front of a steamroller?', Forthcoming, Review of Financial Studies . 
Duffie, D. \& Lando, D. (2001), 'Term structures of credit spreads with incomplete accounting information', Econometrica 69(3), 633-664.

Ericsson, J., Reneby, J. \& Wang, H. (2006), 'Can structural models price default risk? evidence from bond and credit derivative markets', Working Paper, McGill University and Stockholm School of Economics .

Fan, H. \& Sundaresan, S. (2000), 'Debt valuation, renegotiations and optimal dividend policy', Review of Financial Studies 13, 1057-1099.

Finger, C. (2002), 'Creditgrades technical document', RiskMetrics Group .

Finger, C. \& Stamicar, R. (2005a), 'Better ingredients', Journal of Credit Risk $\mathbf{1}(3), 89-97$.

Finger, C. \& Stamicar, R. (2005b), 'Incorporating equity derivatives into the creditgrades model', Working Paper, RiskMetrics Group .

Hogan, S., Jarrow, R., Teo, M. \& Warachka, M. (2004), 'Testing market efficiency using statistical arbitrage with applications to momentum and value strategies', Journal of Financial Economics 73, 525-565.

Hull, J., Predescu, M. \& White, A. (2004), 'The relationship between credit default swap spreads, bond yields, and credit rating announcements', Journal of Banking and Finance 28, 2789-2811.

Jones, E., Mason, S. \& Rosenfeld, E. (1984), 'Contingent claims analysis of corporate capital structures: An empirical investigation', Journal of Finance 39, 611-627.

Lando, D. (2004), 'Credit risk modeling: Theory and applications', Princeton University Press .

Lando, D. \& Mortensen, A. (2005), 'Revisiting the slope of the credit curve', Journal of Investment Management 3(4), 6-32.

Leland, H. E. (1994), 'Corporate debt value, bond covenants, and optimal capital structure', The Journal of Finance 49(4), 1213-1252.

Leland, H. E. \& Toft, K. B. (1996), 'Optimal capital structure, endogenous bankruptcy, and the term structure of credit spreads', The Journal of Finance 51(3), 987-1019. 
Longstaff, F. A., Mithal, S. \& Neis, E. (2005), 'Corporate yield spreads: Default risk or liquidity? new evidence from the credit default swap market', The Journal of Finance 60(5), 2213-2253.

Mitchell, M. \& Pulvino, T. (2001), 'Characteristics of risk and return in risk arbitrage', The Journal of Finance 56(6), 2135-2175.

Mitchell, M., Pulvino, T. \& Stafford, E. (2002), 'Limited arbitrage in equity markets', The Journal of Finance 57(2), 551-584.

Norden, L. \& Weber, M. (2004), 'Information efficiency of credit default swap and stock markets: The impact of credit rating announcements', Journal of Banking and Finance 28, 2813-2843.

Reiner, E. \& Rubinstein, M. (1991), 'Breaking down the barriers', Risk Magazine 4, 28-35.

Schaefer, S. M. \& Strebulaev, I. (2004), 'Structural models of credit risk are useful: Evidence from hedge ratios on corporate bonds', Working Paper, London Business School.

Skorecki, A. (2004), 'Hedge funds fill a strategy gap', Finacial Times (July 21), p.43.

Stohs, M. H. \& Mauer, D. C. (1996), 'The determinants of corporate debt maturity structure', The Journal of Business 69(3), 279-312.

Vassalou, M. \& Xing, Y. (2004), 'Default risk in equity returns', The Journal of Finance 59(2), 831-868.

Yu, F. (2006), 'How profitable is capital structure arbitrage?', Financial Analysts Journal 62(5), 47-62.

Zuckerman, G. (2005), 'Hedge funds stumble even when walking - 'conservative' wagers turn sour, leading to fears of a shakeout; a one-two punch on a GM bet', The Wall Street Journal (May 18), p.C1. 
Table 1: Sample Characteristics

This table reports sample characteristics for the 221 obligors. First, the average characteristics are calculated for each obligor over time, then averaged across firms. The statistics are presented across the senior unsecured credit rating from Standard \& Poor's. $N$ is the number of obligors and spread is the 5-year composite CDS quote. While the historical equity volatility $H V$ is calculated from a 250-day rolling window of equity returns, the implied equity volatility $I V$ is inferred from 30-day at-the-money put options. The leverage ratio lev is total liabilities divided by the sum of total liabilities and equity market capitalization, and size is the sum of total liabilities and equity market capitalization in millions of dollars. Finally, corr is the correlation between changes in the CDS spread and the equity value, averaged across ratings.

\begin{tabular}{lccccccc}
\hline Rating & N & Spread & HV & IV & Lev. & Size & Corr. \\
\hline AAA & 4 & 16 & 0.284 & 0.227 & 0.197 & 142,619 & -0.107 \\
AA & 11 & 23 & 0.267 & 0.257 & 0.216 & 95,237 & -0.050 \\
A & 80 & 40 & 0.305 & 0.293 & 0.354 & 40,274 & -0.089 \\
BBB & 109 & 103 & 0.346 & 0.337 & 0.502 & 25,431 & -0.124 \\
BB & 15 & 270 & 0.386 & 0.377 & 0.524 & 13,667 & -0.056 \\
B & 1 & 355 & 0.554 & 0.555 & 0.564 & 34,173 & -0.261 \\
NR & 1 & 172 & 0.229 & 0.219 & 0.450 & 11,766 & -0.129 \\
\hline
\end{tabular}


Table 2: Descriptive Statistics of Implied Parameters

This table reports the central implied parameters from CreditGrades and Leland \& Toft (1996), calibrated with a historical volatility $H V$ and option-implied volatility $I V$. While the first measure is calculated from a 250-day rolling window of equity returns, the latter is implied from 30-day at-the-money put options. The descriptive statistics for the payout rate, global recovery and bond recovery are calculated across obligors. The remaining variables are first averaged over time, before the statistics are calculated across obligors. The equity value, asset value and default barrier are measured in millions of dollars. The upper three rows report the summary statistics of calibration targets from the equity and equity options market. The global recovery rate is the mean global recovery on all liabilities of the firm, while the bond recovery is the recovery rate on the specific debt issue underlying the CDS. Finally, the payout rate is calculated from historical dividend yields and relative interest expenses.

\begin{tabular}{|c|c|c|c|c|c|}
\hline Variable & Mean & Median & Std. dev. & Min & $\operatorname{Max}$ \\
\hline Equity value & 20,592 & 9,479 & 33,425 & 919 & 238,995 \\
\hline $\mathrm{HV}$ & 0.329 & 0.313 & 0.106 & 0.175 & 0.989 \\
\hline IV & 0.318 & 0.302 & 0.090 & 0.135 & 0.717 \\
\hline \multicolumn{6}{|c|}{ Panel A. CreditGrades HV } \\
\hline Asset value & 29,895 & 14,839 & 46,655 & 1,360 & 337,381 \\
\hline Asset vol. & 0.228 & 0.213 & 0.085 & 0.084 & 0.583 \\
\hline Default barrier & 8,556 & 3,846 & 15,892 & 59 & 154,585 \\
\hline Global rec. & 0.799 & 0.573 & 0.772 & 0.009 & 6.025 \\
\hline \multicolumn{6}{|c|}{ Panel B. CreditGrades IV } \\
\hline Asset value & 26,189 & 12,914 & 40,418 & 1111 & 294,685 \\
\hline Asset vol. & 0.232 & 0.227 & 0.079 & 0.0843 & 0.552 \\
\hline Default barrier & 4,901 & 2,199 & 9,071 & 14 & 93,838 \\
\hline Global rec. & 0.549 & 0.285 & 0.719 & 0.0097 & 5.715 \\
\hline \multicolumn{6}{|c|}{ Panel C. Leland \& Toft HV } \\
\hline Asset value & 34,837 & 18,100 & 53,727 & 2,008 & 417,807 \\
\hline Asset vol. & 0.179 & 0.167 & 0.073 & 0.0382 & 0.446 \\
\hline Default barrier & 12,445 & 5,939 & 32,871 & 591 & 374,849 \\
\hline Bond rec. & -17.410 & -0.443 & 129.611 & $-1,858$ & 0.919 \\
\hline Payout rate & 0.020 & 0.020 & 0.011 & 0 & 0.059 \\
\hline \multicolumn{6}{|c|}{ Panel D. Leland \& Toft IV } \\
\hline Asset value & 34,502 & 17,897 & 52,035 & 1972 & 373,672 \\
\hline Asset vol. & 0.167 & 0.156 & 0.069 & 0.0077 & 0.413 \\
\hline Default barrier & 12,762 & 6,105 & 33,360 & 593 & 364,376 \\
\hline Bond rec. & -3.554 & 0.233 & 18.256 & -222.69 & 0.835 \\
\hline Payout rate & 0.020 & 0.020 & 0.011 & 0 & 0.059 \\
\hline
\end{tabular}




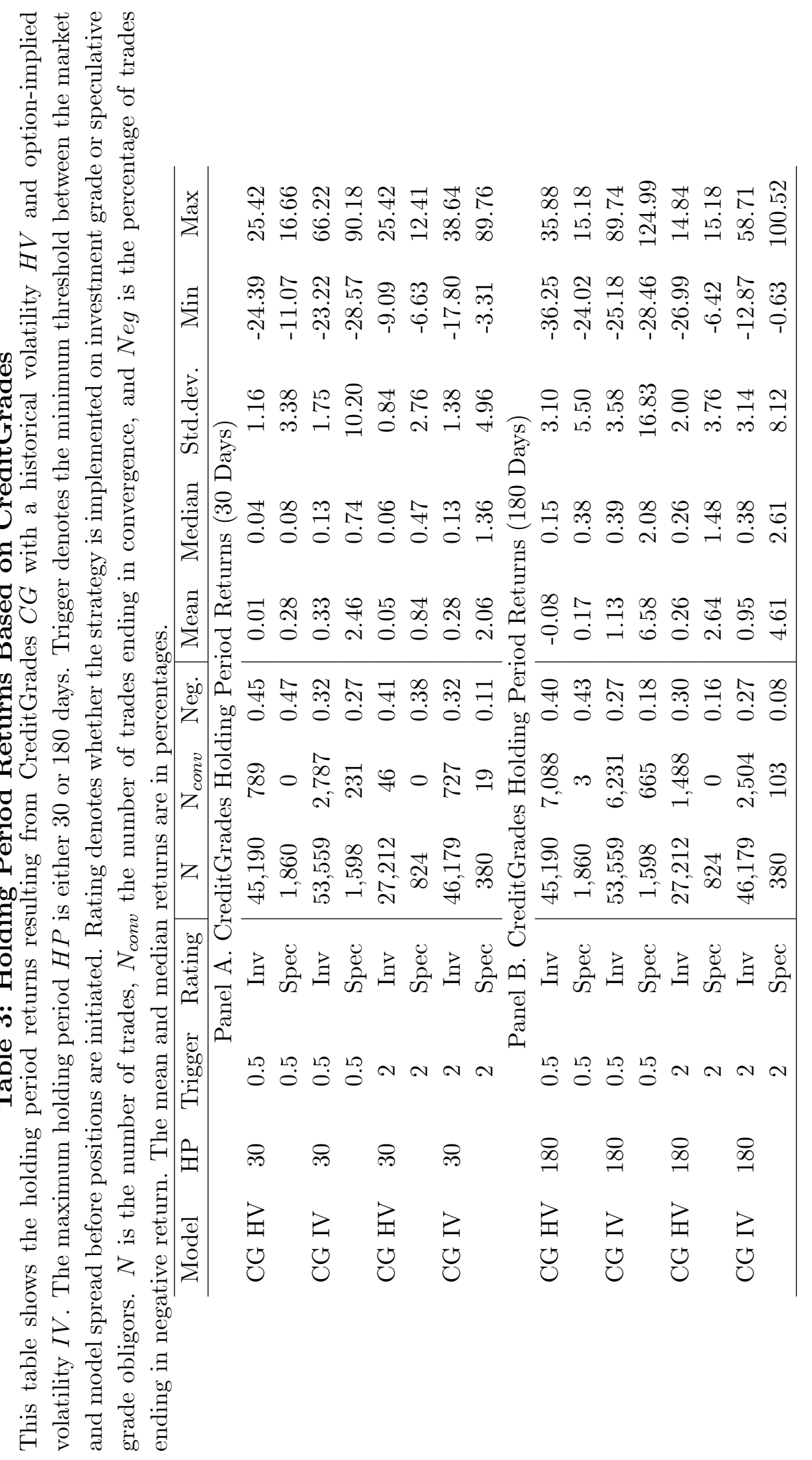




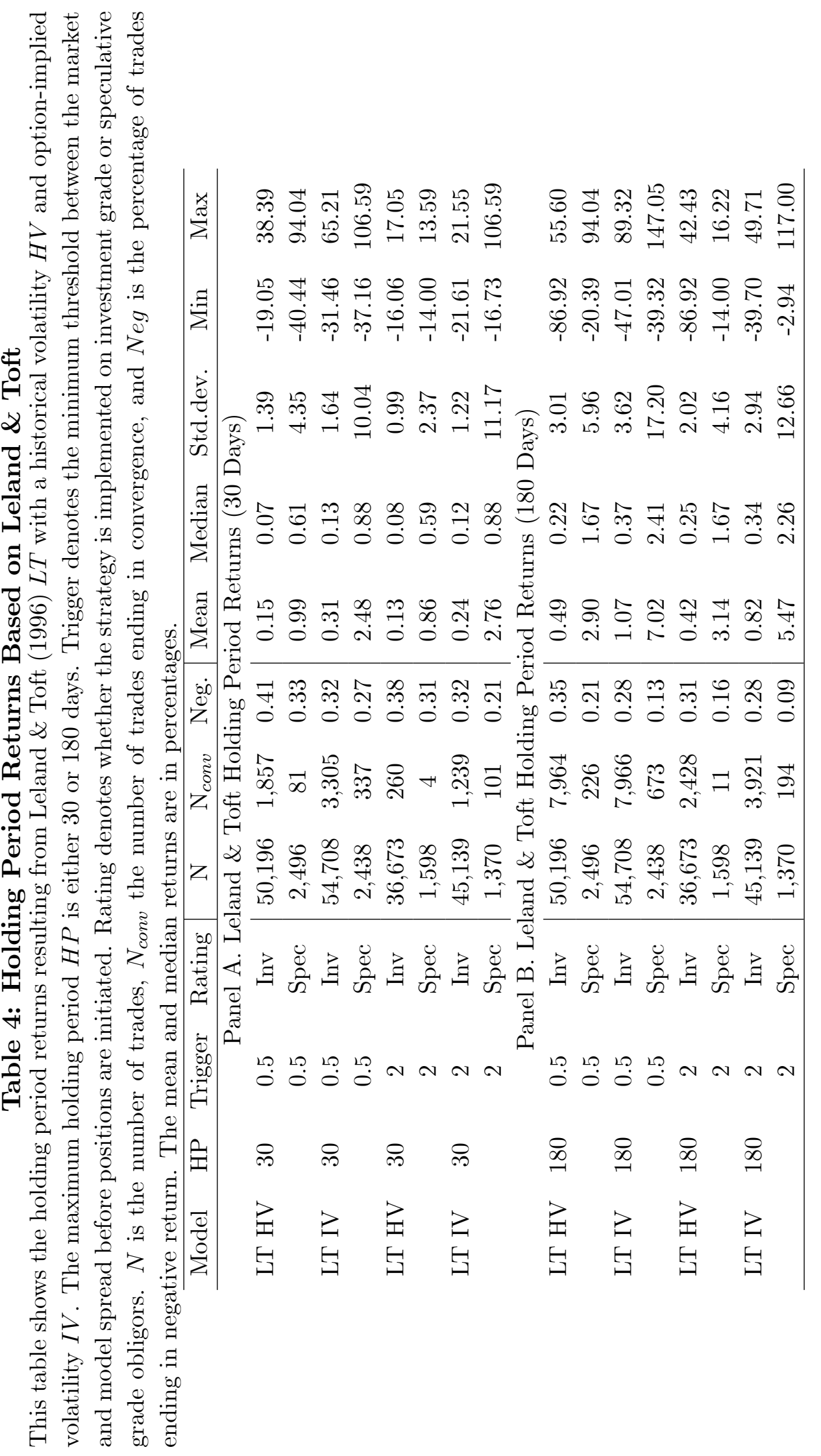


चี

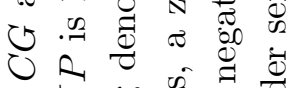

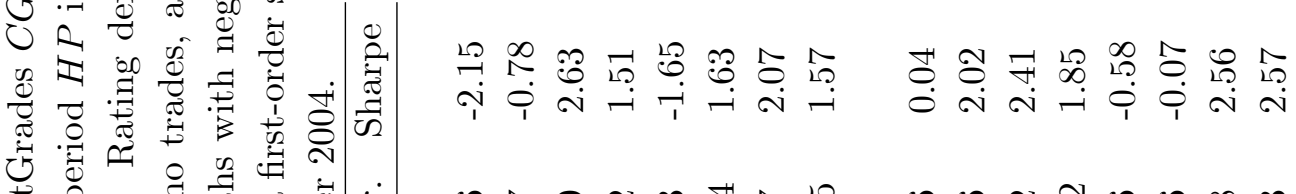

苞

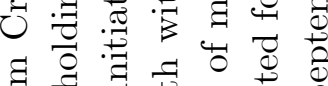

घี

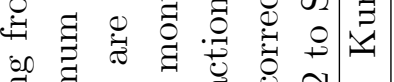

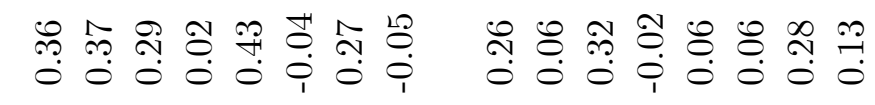

当

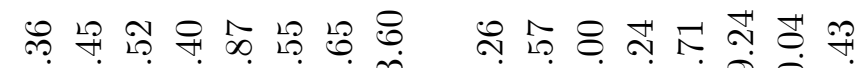

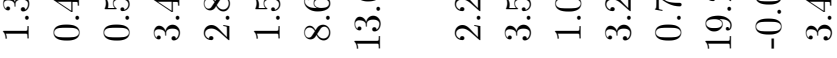

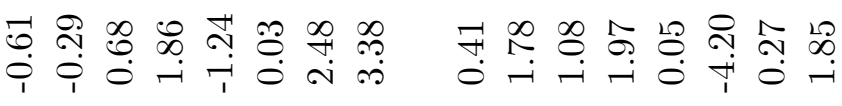

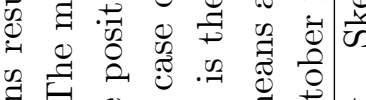
$\exists$ ․

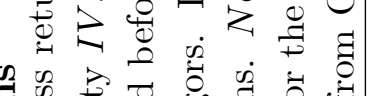

ㄷำ

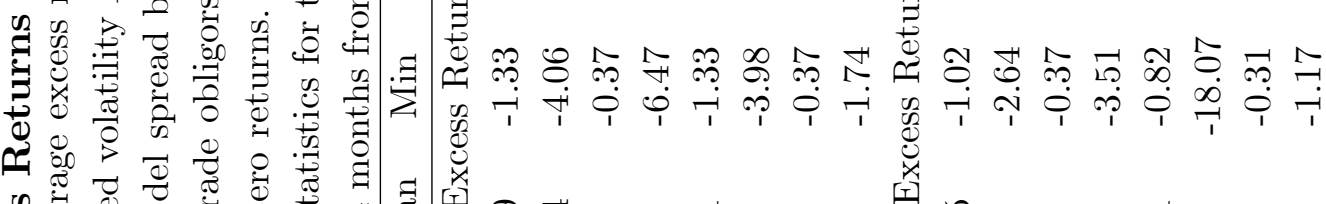

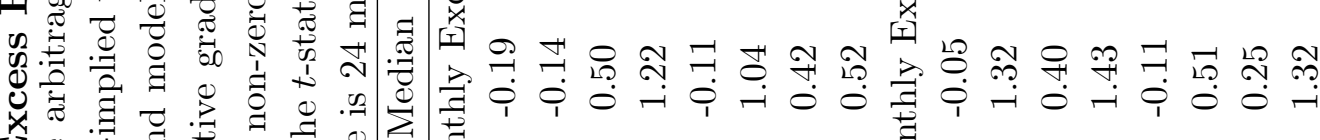

기

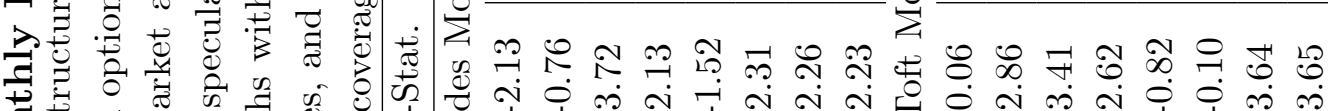
范

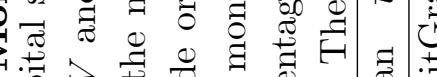

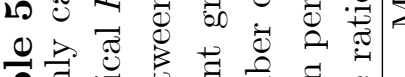

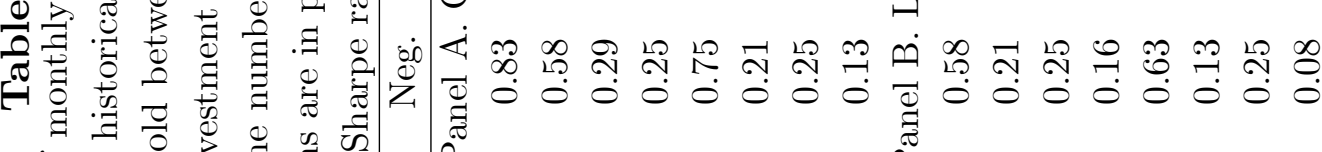
फ 趈

茎

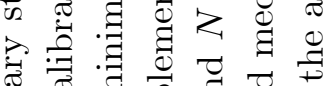

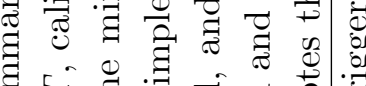

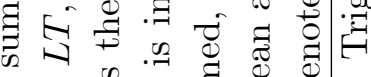

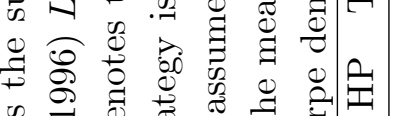

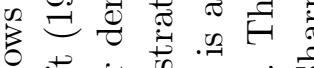

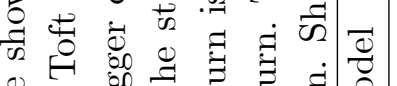

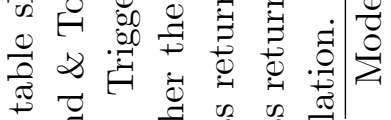

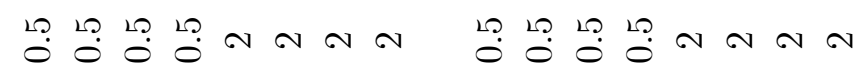
कृ

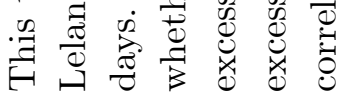

\begin{tabular}{|c|c|c|c|c|c|}
\hline$\underset{\sim}{\infty}$ & $\underset{\infty}{\infty}$ & $\underset{\sim}{\infty}$ & $\underset{\infty}{\infty}$ & $\underset{\infty}{\infty}$ & $\underset{\infty}{\infty}$ \\
\hline & -1 & $z$ & 出 & & 主 \\
\hline 0 & ن & U & $\vec{G}$ & 䛼 & 舁 \\
\hline
\end{tabular}




\section{Table 6: Regression Results}

This table reports the results from regressing capital structure arbitrage monthly percentage excess returns on the excess returns of equity and bond market portfolios. The models underlying the strategy are CreditGrades $C G$ and Leland \& Toft (1996) LT, calibrated with a historical $H V$ and option-implied volatility $I V$. The strategy is implemented separately on investment grade and speculative grade obligors. S\&PINDS is the excess return on the $\mathrm{S} \& \mathrm{P}$ Industrial Index. $L H I B A A I$ and $L H H Y B B I$ are the excess returns on the Lehman Brothers Baa and Ba Intermediate Index, respectively. The coverage is 24 months beginning October 2002 and ending September 2004. Standard errors are shown in parantheses, and ${ }^{* * *},{ }^{* *}$ and ${ }^{*}$ denote significance at 1,5 and 10 percent, respectively.

\begin{tabular}{cccccc}
\hline Strategy & Intercept & S\&PINDS & LHIBAAI & LHHYBBI & $R^{2}$ \\
\hline CG HV Inv & $-0.57^{*}$ & 0.09 & 7.29 & $-14.40^{*}$ & 0.21 \\
& $(0.28)$ & $(2.27)$ & $(7.06)$ & $(7.80)$ & \\
CG HV Spec & 1.96 & -2.61 & -53.73 & $77.25^{*}$ & 0.17 \\
& $(1.48)$ & $(12.02)$ & $(37.30)$ & $(41.19)$ & \\
CG IV Inv & -0.15 & 6.13 & $-26.18^{* *}$ & 12.77 & 0.35 \\
& $(0.49)$ & $(3.96)$ & $(12.29)$ & $(13.58)$ & \\
CG IV Spec & 3.76 & 9.11 & -45.06 & 81.11 & 0.16 \\
& $(2.21)$ & $(18.00)$ & $(55.87)$ & $(61.70)$ & \\
LT HV Inv & $-0.59^{* *}$ & 1.51 & -1.86 & -8.44 & 0.32 \\
& $(0.21)$ & $(1.74)$ & $(5.41)$ & $(5.98)$ & \\
LT HV Spec & 1.76 & 33.36 & 39.03 & -40.44 & 0.08 \\
& $(3.18)$ & $(25.91)$ & $(80.41)$ & $(88.80)$ & \\
LT IV Inv & 0.27 & 2.34 & $-13.22^{*}$ & $12.13^{*}$ & 0.32 \\
& $(0.24)$ & $(1.98)$ & $(6.78)$ & $(6.14)$ & \\
LT IV Spec & $7.04^{* * *}$ & -22.35 & -21.91 & $121.69^{*}$ & 0.30 \\
& $(2.22)$ & $(18.04)$ & $(55.98)$ & $(61.82)$ & \\
\hline
\end{tabular}


Figure 1: Sears, Roebuck and Company

This figure illustrates the fundamentals behind capial structure arbitrage. In panel A, we depict market CDS spreads together with model spreads in Leland \& Toft (1996) $L T$ inferred from historical $H V$ and option-implied volatilities $I V$. In panel $\mathrm{B}$, the corresponding spreads are depicted based on CreditGrades $C G$. Panel $\mathrm{C}$ depicts the historical and option-implied volatility, where the first is calculated from a rolling 250day window of equity returns, and the latter is inferred from 30-day at-the-money puts. Finally, panel D illustrates the total market value of equity in millions of dollars.
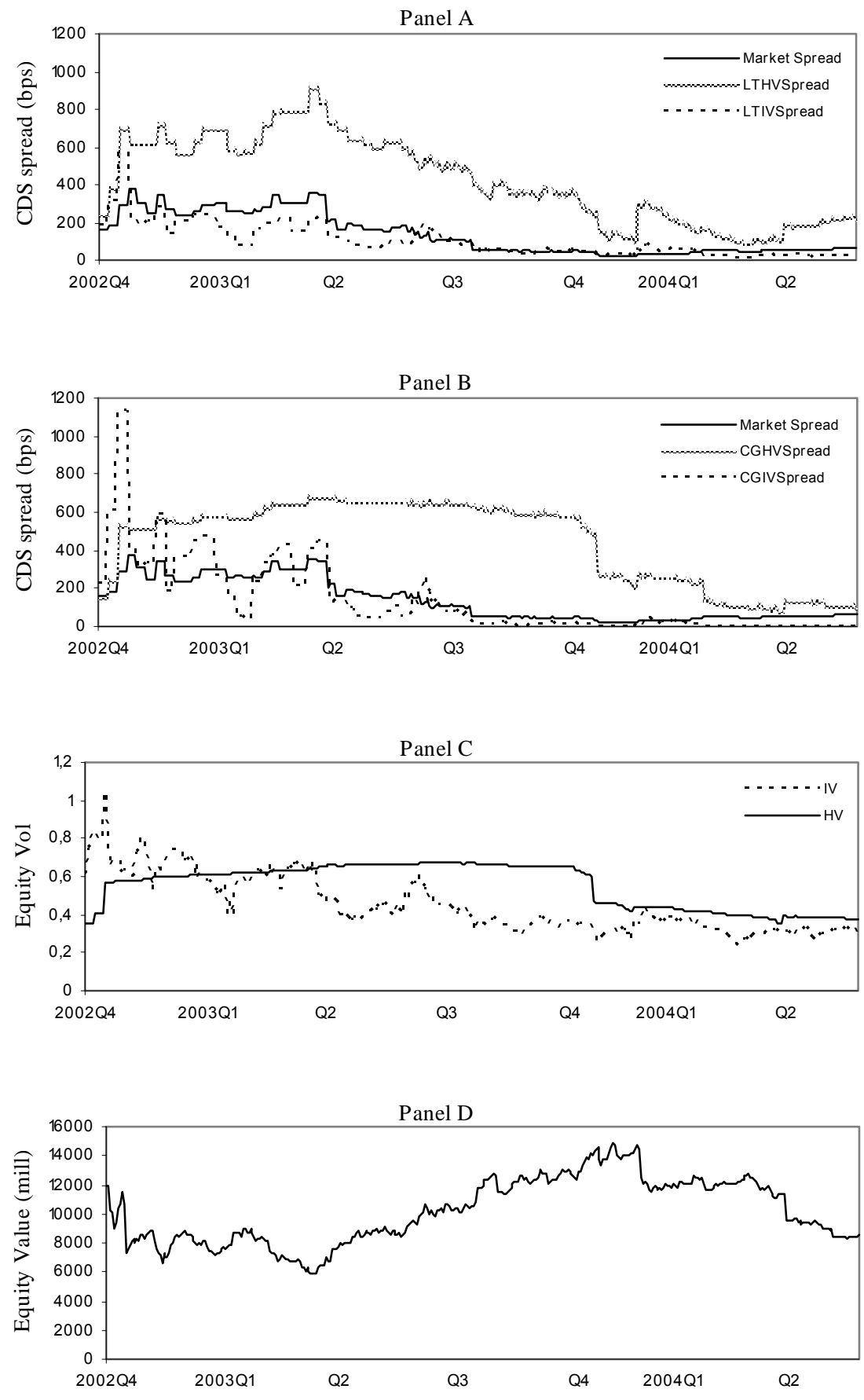


\section{Figure 2: Time Warner}

This figure illustrates the fundamentals behind capial structure arbitrage. In panel A, we depict market CDS spreads together with model spreads in Leland \& Toft (1996) $L T$ inferred from historical $H V$ and option-implied volatilities $I V$. In panel $\mathrm{B}$, the corresponding spreads are depicted based on CreditGrades $C G$. Panel $\mathrm{C}$ depicts the historical and option-implied volatility, where the first is calculated from a rolling 250day window of equity returns, and the latter is inferred from 30-day at-the-money puts. Finally, panel D illustrates the total market value of equity in millions of dollars.
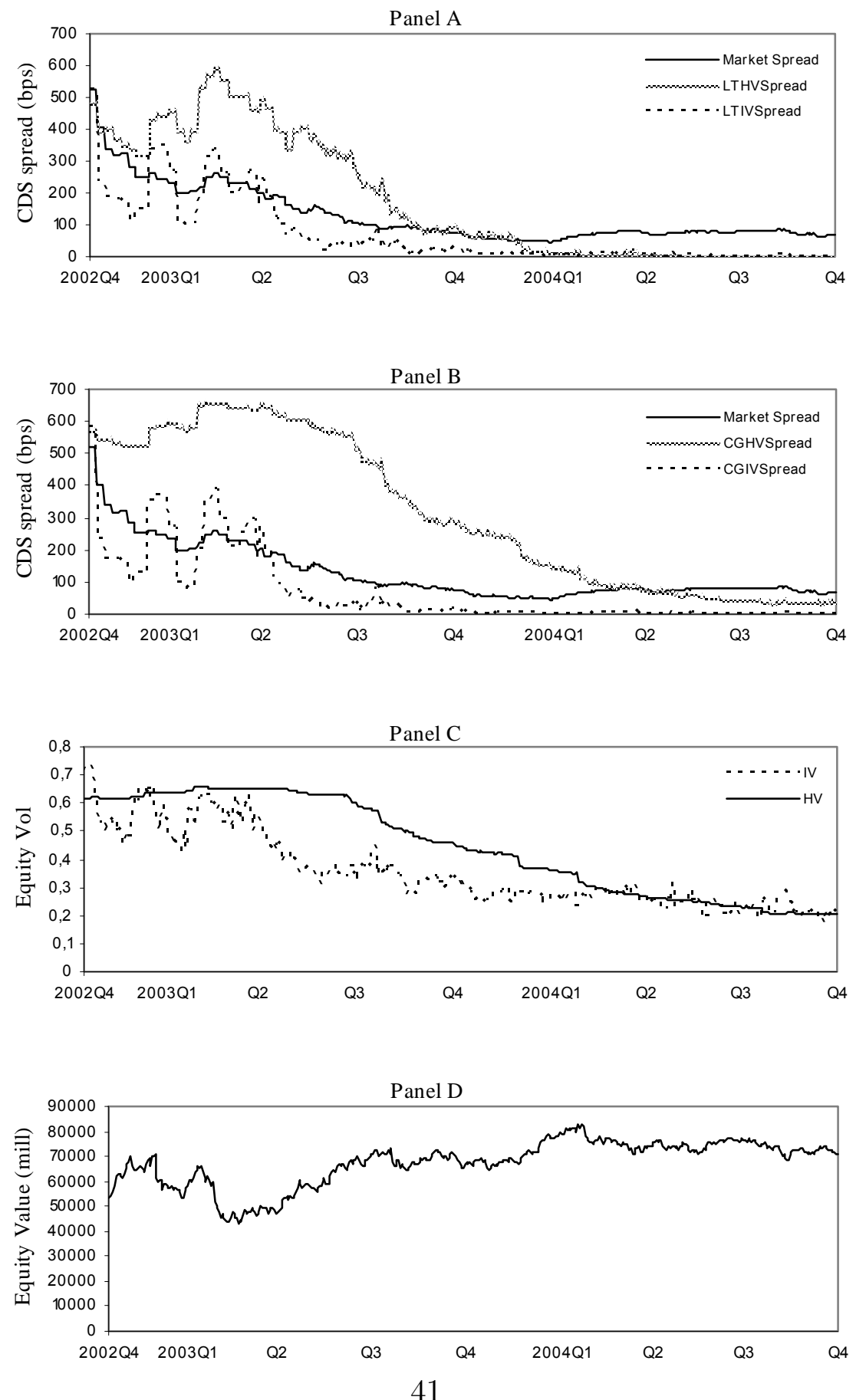


\section{Figure 3: Motorola}

This figure illustrates the fundamentals behind capial structure arbitrage. In panel A, we depict market CDS spreads together with model spreads in Leland \& Toft (1996) $L T$ inferred from historical $H V$ and option-implied volatilities $I V$. In panel $\mathrm{B}$, the corresponding spreads are depicted based on CreditGrades $C G$. Panel $\mathrm{C}$ depicts the historical and option-implied volatility, where the first is calculated from a rolling 250day window of equity returns, and the latter is inferred from 30-day at-the-money puts. Finally, panel D illustrates the total market value of equity in millions of dollars.
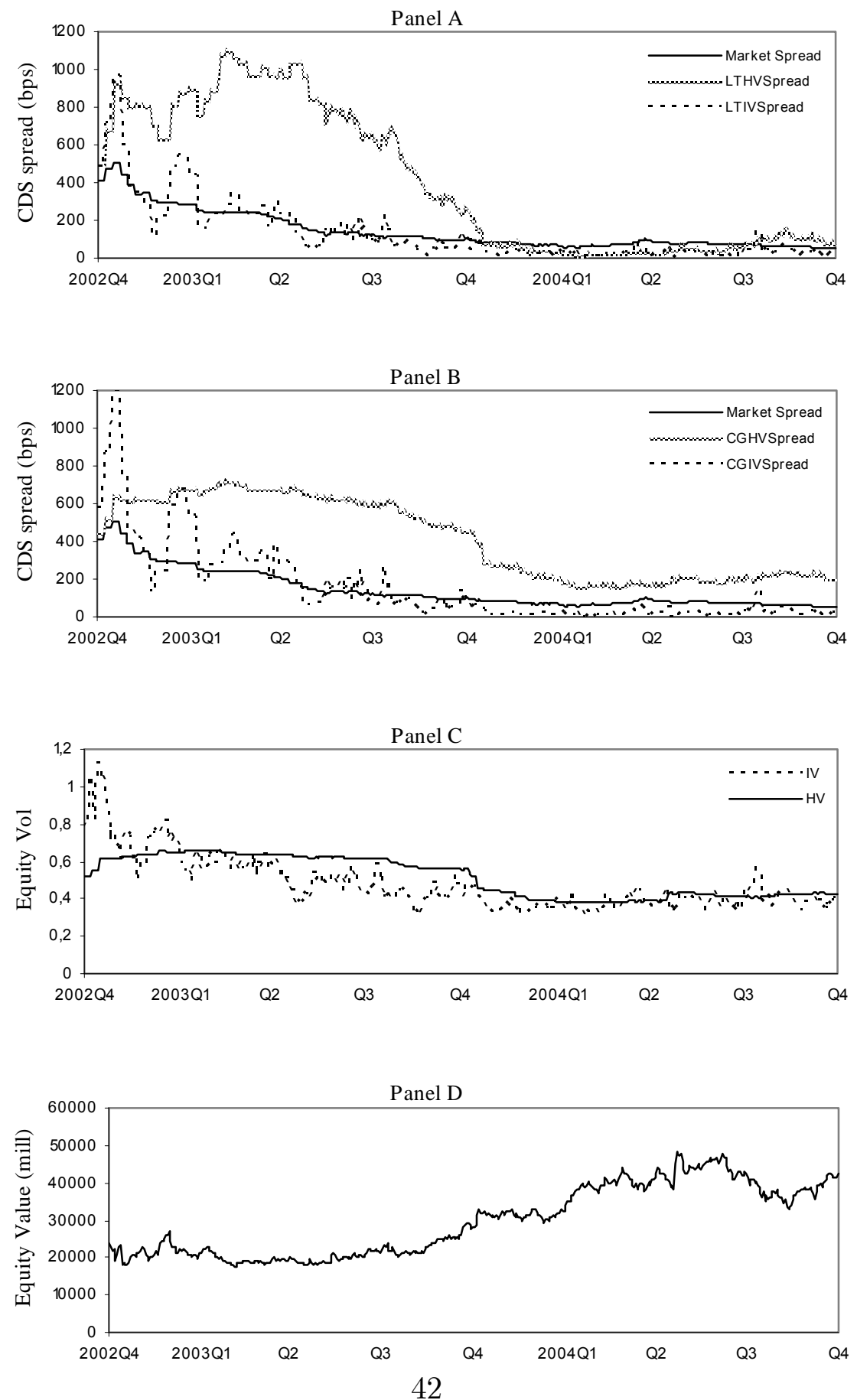


\section{Figure 4: Mandalay Resort Group}

This figure illustrates the fundamentals behind capial structure arbitrage. In panel A, we depict market CDS spreads together with model spreads in Leland \& Toft (1996) $L T$ inferred from historical $H V$ and option-implied volatilities $I V$. In panel $\mathrm{B}$, the corresponding spreads are depicted based on CreditGrades $C G$. Panel $\mathrm{C}$ depicts the historical and option-implied volatility, where the first is calculated from a rolling 250day window of equity returns, and the latter is inferred from 30-day at-the-money puts. Finally, panel D illustrates the total market value of equity in millions of dollars.
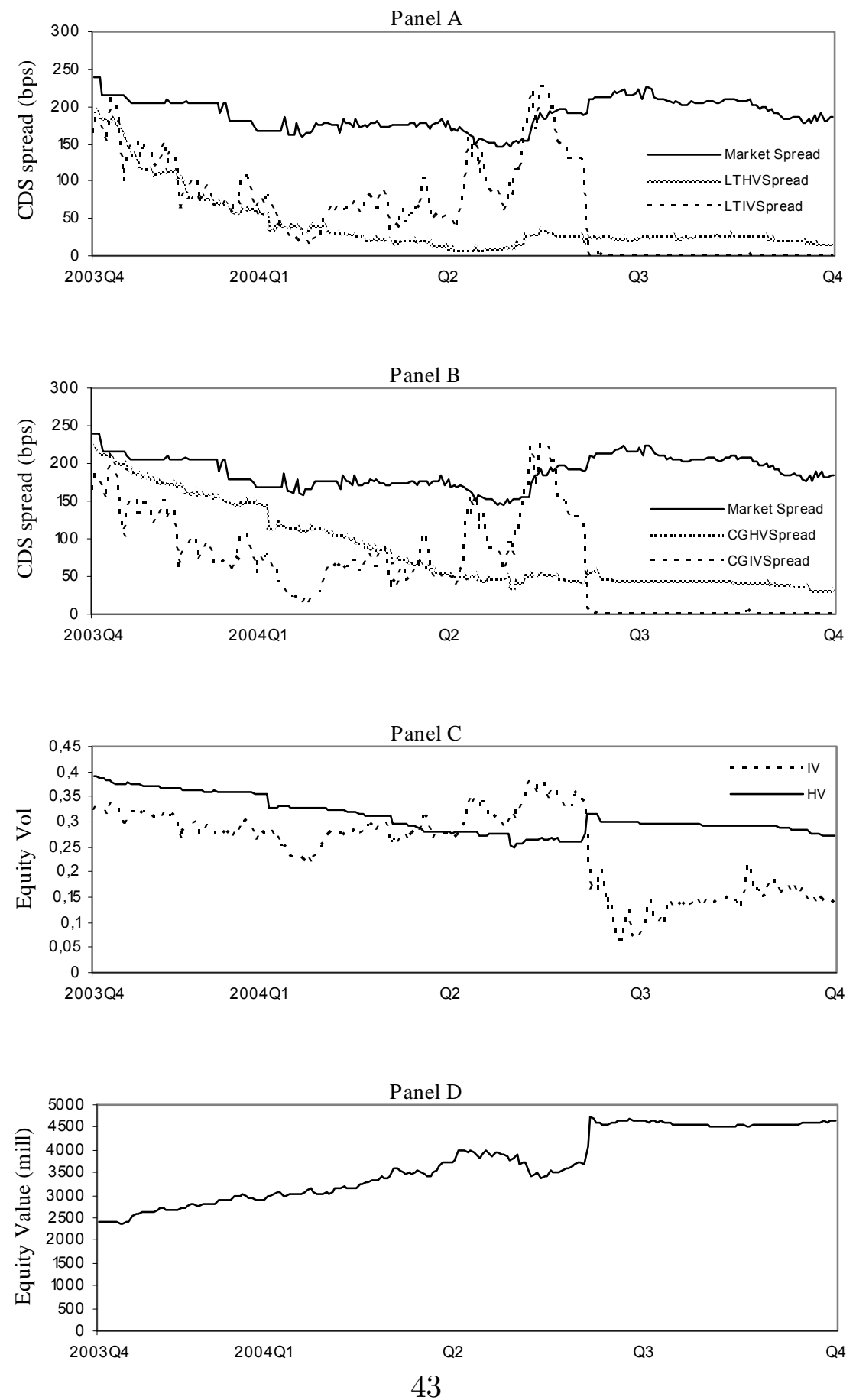